\title{
Ontogenetic Shift in Mouth Opening Mechanisms in a Catfish (Clariidae, Siluriformes): A Response to Increasing Functional Demands
}

\author{
D. Adriaens, ${ }^{1 *}$ P. Aerts, ${ }^{2}$ and W. Verraes ${ }^{1}$ \\ ${ }^{1}$ Ghent University, Vertebrate Morphology, Ghent, Belgium \\ ${ }^{2}$ University of Antwerp (UIA), Department of Biology, Antwerpen, Belgium
}

\begin{abstract}
During ontogeny, larval fish have to deal with increasing nutritional and respiratory demands as they grow. As early ontogeny is characterized by an increasing complexity of moving structural elements composing a fish skull, some constraints will have to be met when developing mechanisms, which enable feeding and respiration, arise at a certain developmental stage. This article focuses on the presence/absence of a possible functional response in mouth opening during ontogeny in Clarias gariepinus. Some reflections are given, based on morphological data, as well as related function-analysis data from the literature. Starting shortly after hatching, a total of up to five different mouth opening mechanisms may become functional. Of these, three may remain functional in the adult. As could be expected, the apparatuses that enable these mechanisms show an increase in complexity, as well as a putative improvement in mouth opening capacity. Initially, two consecutive mechanisms may allow a restricted depression of the lower jaw (both pas-
\end{abstract}

During their early life history, teleosts are continuously confronted with changing environmental factors to which they have to respond in an adequate manner in order to ensure their survival. As a consequence, the early ontogeny can be regarded as a trade-off between the race to respond to functional demands and the developmental process of Bauplan differentiation (Galis et al., 1994; Osse et al., 1997). Events during the early life history of fishes, which introduce substantial changes in functional demands, involve respiration, feeding, or predator avoidance (Otten, 1982, 1989, 1990; Osse and van den Boogaart, 1995; Hunt von Herbing et al., 1996a; Fuiman, 1997; Osse et al., 1997).

The adult African catfish Clarias gariepinus (Burchell, 1822) (Siluriformes: Clariidae) has been suggested to exhibit an opportunistic feeding behavior (Thomas, 1966). This is supported by morphological evidence of feeding structures, as well as stomach analyses (Groenewald, 1964; Teugels, 1986; Adriaens and Verraes, 1996, 1998; Adriaens et al., 1997). However, at the time C. gariepinus specimens reach the size when they can fully exploit their opportunistic feeding behavior, they have survived a sively and actively). Synchronously, two more mechanisms may arise, which involve the coupling of the hyoid depression to the mouth opening. At about $11 \mathrm{~mm}$ SL a fifth mechanism becomes established, better known as the opercular mouth opening mechanism. An overlapping chronology of functionality of the different mechanisms, as well as differences in efficiencies, could be an indication of the absence of a true critical period in $C$. gariepinus (at least in relation to mouth opening), as well as the possible presence of a shift in feeding type. Finally, the coupling of the chronology of the shift in mouth opening mechanisms and several morphological, behavioral, and physiological changes during ontogeny, related to feeding and respiration, make it possible to distinguish five important phases in the early life history of $C$. gariepinus. J. Morphol. 247: 197-216, 2001. ㅇ 2001 Wiley-Liss, Inc.

KEY WORDS: catfish; ontogeny; mouth opening; functional demands

larval phase featuring presumably less opportunistic feeding. Not only will the head size determine the kind of food that can be eaten, the size of the yolk sac and the structural differentiation of the feeding apparatus will be as restricting (Greenwood, 1955; Hecht and Appelbaum, 1987; Kohno et al., 1996b). Ontogenetic shifts in dietary demands are a common feature in teleosts (Thomas, 1966; Segnini and Bastardo, 1995; Olson, 1996; Lowe et al., 1996; Rowe and Chisnall, 1996; Cook, 1996). In terms of "symmorphosis" (i.e., the quantitative match between the functional capacity of an organism and the functional demands they have to cope with), it can be expected that changes in diet and food particle size during ontogeny will be coupled to changes in feeding mechanisms (Weibel and Taylor, 1981; Galis et al., 1994). Not only will the larva have to adapt to

Contract grant sponsors: the IWT and FWO; Contract grant number: G.0388.00

\footnotetext{
*Correspondence to: Dominique Adriaens, Ghent University, Vertebrate Morphology, K.L. Ledeganckstraat 35, B-9000 Gent, Belgium. E-mail: dominique.adriaens@rug.ac.be
} 
take up larger food items, it may also have to increase food capturing and manipulation efficiency (Osse, 1990). Larvae can do so by 1) making a complete use of those structures present, and/or 2) enlarging the capacity of these structures in response to changes in demand (Galis et al., 1994). It is, however, crucial for a developing larva to do so at a low energy cost (Galis and de Jong, 1988) or to minimize energy loss during prey capture (Osse and Drost, 1989; Osse, 1990). Equally important is the timing of the morphological transformations in relation to the chronology of changes in functional demands and nutritional requirements (Otten, 1982; Holden and Bruton, 1994).

Apart from feeding, the efficiency of the respiratory apparatus will have to increase as well, as gas exchange will no longer be sustained by cutaneous respiration at a certain moment in a growing larva (Osse, 1989, 1990; Holden and Bruton, 1994).

In this study, it is hypothesized that such a relation between functional demands and structural differentiations may exist in the cranial Bauplan as well. In order to demonstrate the existence of such a relation, the ontogeny of mouth opening is investigated, with links being made with arising functional demands during early life history where possible. The functioning of possible mouth opening mechanisms is deduced from morphological data, but support for the assumptions is based on kinematic data from the literature, as well as calculations of efficiencies. Although logical in an evolutionary context, however, most conclusions remain speculative. Some assumptions have been made previously (Adriaens and Verraes, 1994), however, on a general basis. This article presents a more detailed survey.

\section{MATERIALS AND METHODS Studied Specimens}

Several specimens of the African catfish Clarias gariepinus (Burchell, 1822), of different standard lengths were used (ranging between $4.1 \mathrm{~mm}$ SL (= standard length) (= 1 day posthatching) and 174.5 mm SL (age unknown)) (see Adriaens and Verraes, 1998: table 1). Eggs were obtained from the Laboratory of Ecology and Aquaculture (Catholic University of Leuven) and raised at a temperature of $25^{\circ} \mathrm{C}$. The older juvenile specimens (100 days posthatching) were commercially raised and obtained from W. Fleure (Someren, The Netherlands). Specimens were sedated (using MS-222 overdose) and fixed in $4 \%$ buffered formaldehyde of paraformaldehydeglutaraldehyde solutions at different time intervals. Clearing and staining followed Hanken and Wassersug (1981), with trypsin being replaced by a $1 \%$ $\mathrm{KOH}$ solution. Cleared specimens were studied using a stereoscopic microscope (WILD M5).

Several specimens were also used for serial sectioning in order to reveal details on myology and ligaments. Embedding was done using Epon or
Paraplast. Sections of 2 and $5 \mu \mathrm{m}$, respectively, were stained with toluidine and an improved trichrome staining according to Mangakis et al. (1964). Sections were studied using a Leitz Diaplan light microscope. Drawings of both cleared and sectioned material were made using a camera lucida. Threedimensional reconstructions of serial sections were done using a commercial software package (PC3D, Jandel Scientific, Sausalito, CA).

\section{Mouth Opening Efficiencies}

Serial sections of two specimens $(5.6$ and $7.2 \mathrm{~mm}$ SL) were used for calculating maximal muscle forces as well as moments. Coordinates of muscle insertion sites were used for calculating the mean fiber length (as separate fibers could hardly be distinguished in these early stages). Muscle volumes were calculated using the PC3D software in order to calculate the physiological cross section area. Maximal output forces $\left(\mathrm{F}_{\max }\right)$ of each muscle were calculated using $26 \mathrm{~N} / \mathrm{cm}^{2}$ as the maximal force per unit of surface (Aerts, 1987; Aerts et al., 1987). Based on the length of the input arms $(l)$, as well as the angle between the input lever and the muscle $(\alpha)$, the moment of each muscle could be calculated $\left(\mathrm{M}=\mathrm{F}_{\max }{ }^{*} \sin (\alpha) * l\right)$.

Data from cleared as well as sectioned specimens of several ontogenetic stages of Clarias gariepinus $(7.2,19.0,21.5,41.9,127.0$, and $147.7 \mathrm{~mm} \mathrm{SL})$ were used to calculate efficiencies of the opercular and hyoid four-bar systems using the model of Aerts and Verraes (1984). This model was also modified in order to calculate the efficiencies of both hyoid and opercular systems at specific angles of mandibular depression, especially output velocities. This dimensionless parameter gives an idea of the difference in input speed of the crank, compared to the output speed of the follower of a four-bar system, taking into account the lengths of the input and output levers. The aims of this modeling are: 1) to distinguish which ontogenetic pattern in efficiency alterations is present; 2) to compare the efficiency of the opercular four-bar system with that of the hyoid four-bar system in several ontogenetic stages; 3) to check to what degree the hyoid and opercular barsystems optimize mouth opening; and 4) to compare the efficiency of the opercular four-bar system in several ontogenetic stages with that of other teleosts (data obtained from Aerts and Verraes, 1984) (see Discussion). Data from the same specimens were also used for calculating the degree of suspensorial abduction during hyoid depression, based on the model of the de Visser and Barel (1996).

\section{RESULTS \\ Mouth Opening Mechanisms}

The detailed morphology of cranial ontogeny has been dealt with in previous articles: chondrocranium (Adriaens and Verraes, 1997a,e), osteocra- 

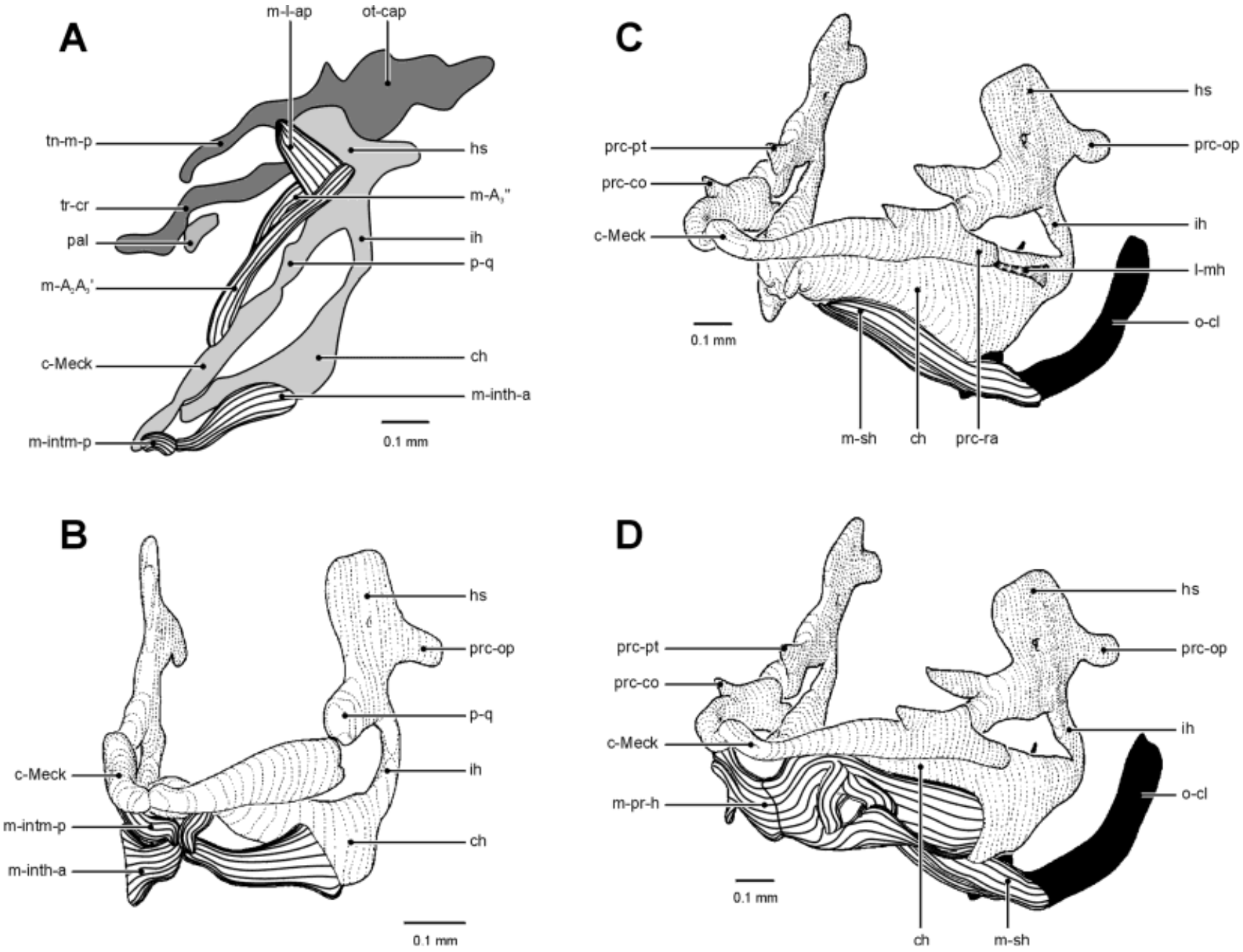

Fig. 1. Morphology of mouth opening apparatuses in Clarias gariepinus during ontogeny. A: Apparatus 1: neurocranium, suspensorium, lower jaw, and hyoid bar of the $5.0 \mathrm{~mm}$ SL stage (modified from Surlemont et al., 1989). B: Apparatus 2: graphical 3D-reconstruction of the same structures, without the neurocranium in the $5.6 \mathrm{~mm}$ SL stage. C: Apparatus 3: graphical 3Dreconstruction of the same structures in the $7.2 \mathrm{~mm}$ SL stage. D: Apparatus 4: same as C. ch, ceratohyale; c-Meck, cartilago Meckeli; hs, hyosymplecticum; ih, interhyale; l-mh, ligamentum mandibulo-hyoideum; $\mathrm{m}_{-} \mathrm{A}_{2} \mathrm{~A}_{3}{ }^{\prime}$, musculus adductor mandibulae $\mathrm{A}_{2} \mathrm{~A}_{3}$; $; \mathrm{m}^{-\mathrm{A}_{3}}$ “', musculus adductor mandibulae $\mathrm{A}_{3}$ ”; $\mathrm{m}$-inth-a, musculus interhyoideus anterior; $\mathrm{m}$-intm-p, musculus intermandibularis posterior; $\mathrm{m}$-l-ap, musculus levator arcus palatini; $\mathrm{m}$-pr-h, musculus protractor hyoidei; $\mathrm{m}$-sh, musculus sternohyoideus; o-cl, os cleithrum; ot-cap, otic capsule; pal, palatinum; p-q, pars quadrata of the pterygoquadratum; prc-co, processus coronoideus; prc-op, processus opercularis of the hyosymplecticum; prc-pt, processus pterygoideus of the pterygoquadratum; prc-ra, processus retroarticularis; tn-m-p, taenia marginalis posterior; tr-cr, trabecula cranii.

nium (Adriaens and Verraes, 1998), and myology (Surlemont et al., 1989; Surlemont and Vandewalle, 1991; Adriaens and Verraes, 1996, 1997b,c,d). Consequently, only those features needed to understand the working of the mouth opening apparatus will be given here. Based on the morphology of the specimens used, a total of five possible mouth opening mechanisms could be distinguished. The results are presented according to the expected chronological order. For each mechanism, the morphology and deduced possible functioning are described.

Mouth opening probably only occurs at about 5.0 $\mathrm{mm}$ SL (corresponding to $48 \mathrm{~h}$ posthatching). The presence of the adductor mandibulae complex, the posterior intermandibular, and anterior interhyoid muscles has been observed in a $4.7 \mathrm{~mm}$ TL specimen; however, no movements of the lower jaw were present as their insertions were still lacking (Surlemont and Vandewalle, 1991). Surprisingly, however, the figures in this article suggest the presence of insertions (as no sectioned material of comparable stages was at hand, this could not be verified).

\section{Mechanism 1 (5.0-5.6 mm SL)}

Form. Both form and function of this mechanism have been described by Surlemont et al. (1989). At hatching, the suspensorium, lower jaw, and hyoid bar arise as a single cartilaginous plate (Fig. 1A). Both lower jaw and hyoid bar are connected to the 
suspensorium by a narrow, pliable region. Shortly after hatching (at about $5.2 \mathrm{~mm}$ TL), the adductor mandibulae, the posterior intermandibular, and anterior interhyoid muscles become attached to both their insertion sites (Surlemont et al., 1989). In their article, Surlemont et al. (1989) surprisingly concluded that "as the muscles likely to lower the mandible are not yet inserted on the skeleton, the lower jaw could come back to its resting position by its own elasticity," after having mentioned the contradictory statement that "some muscles are provided with both proximal and distal insertions:..., the protractor hyoidei,..." The insertion of this protractor, which at that stage still consists of the distinct intermandibularis posterior and interhyoideus anterior, on both the lower jaw and the ceratohyal could be observed in a $5.8 \mathrm{~mm}$ TL specimen, in which the lower jaw still appeared to be continuous with the suspensorium.

Function. If indeed the posterior intermandibular and anterior interhyoid muscle are attached to the lower jaw and the ceratohyal in this early stage, mouth opening may be more efficient, as proposed by Surlemont et al. (1989). It would imply that mouth opening could occur passively as well as through muscular contraction. The passive mechanism would rely on the elastic properties of the cartilaginous connection between lower jaw and suspensorium, as strain energy stored in that connection during adductor mandibulae contraction would restore the mouth to its original, slightly opened position during adductor relaxation (Fig. 2A). The active mechanisms would involve the muscular retraction of the lower jaw by the posterior intermandibularis and anterior interhyoideus muscles. However, some drawbacks have to be considered: 1) in order for the passive mechanism to work, the strain energy released during adductor mandibulae relaxation must generate a mouth opening force which exceeds the resistive force of the extending adductor muscle fibers, as well as that needed to displace the water mass below the lower jaw. As a consequence, maximal mouth opening in this mechanism could be reached very quickly, thus enabling very little mouth opening. 2) Further mouth opening could then be enabled due to the active mechanism involving the muscles interconnecting the lower jaw with the hyoid bar. However, at this 5.2 $\mathrm{mm}$ TL stage, the sternohyoideus muscle (needed for fixation of the hyoid bar) is still unattached to the hyoid bar (Surlemont et al., 1989), which could thus annul any mouth opening action. Even then, arguments can be made that suggest a possible (but restricted) mouth opening action of this mechanism, as described in Mechanism 2.

\section{Mechanism 2 (5.6-19.2 $\mathrm{mm}$ SL)}

Form. At approximately 5.6 mm SL, Meckel's cartilage becomes detached from the suspensorium and an articulation is formed. The hyoid bar is still continuous with the suspensorium through a cartilaginous interhyal. The posterior intermandibular and anterior interhyoid muscles still form a distinct $\mathrm{X}$-shaped muscle pair, interconnecting the lower jaw with the hyoid bar (Fig. 1B).

Function. Once a true articulation is formed between the lower jaw and the suspensorium, strain energy can no longer be stored, thus annulling the previously mentioned passive mechanism. However, a true articulation also implies a substantial reduction of resistive forces in the connection between lower jaw and suspensorium during mouth opening. This would improve the mouth opening through muscular contraction (Fig. 2B). However, theoretically, contraction of the posterior intermandibular and anterior interhyoid muscle complex may not only result in a lower jaw depression, but in a hyoid elevation as well. As the sternohyoideus cannot prevent this action (due to the absence of its insertion), this action could thus partially nullify mouth opening. Although the differences in stresses in the mandibular and hyoid connections with the suspensorium alone could allow mouth opening between 5.6 and $6.2 \mathrm{~mm}$ SL, unfavorable muscle-skeleton configurations might overrule this. Differences in moment about the mandibular articulation and the hyoid connection with the suspensorium can thus make this mechanism more effective or may overrule the resistive forces. In the $5.6 \mathrm{~mm}$ SL specimen, the calculated moments, which could be generated by the intermandibular and interhyoid muscles about the interhyal, are much lower than that about the mandibular articulation (21.17 and 32.59 $\mu \mathrm{N} . \mu \mathrm{m}$, respectively). In the $7.2 \mathrm{~mm}$ SL specimen, this calculated difference is substantially greater (66.18 and $222.59 \mu \mathrm{N} . \mu \mathrm{m}$, respectively). One has to bear in mind that these moments represent a static situation, which is not the case in a dynamically mouth-opening larva. The only moments that could provide a conclusive idea of the efficiency of the mouth opening mechanism is that at the starting position, i.e., with the mouth closed. In the examined specimens, however, the mouths were partially open (gape of about $30^{\circ}$ and $20^{\circ}$ in the 5.6 and 7.2 $\mathrm{mm}$ SL specimens, respectively), so some precaution has to be taken in considering these results.

Theoretically, this mechanism could remain functional until the interhyal becomes detached from the hyoid bar (or the suspensorium), which occurs at about $19.2 \mathrm{~mm}$ SL (personal observations and Vandewalle et al., 1985).

\section{Mechanism 3 (6.2-... mm SL)}

Form. At $6.2 \mathrm{~mm}$ SL, the articulatory facet of the lower jaw has become more pronounced, even though ossifications surrounding this facet are still lacking (Fig. 1C). Posterior to the articulation, Meckel's cartilage has formed a pronounced retroar- 
A

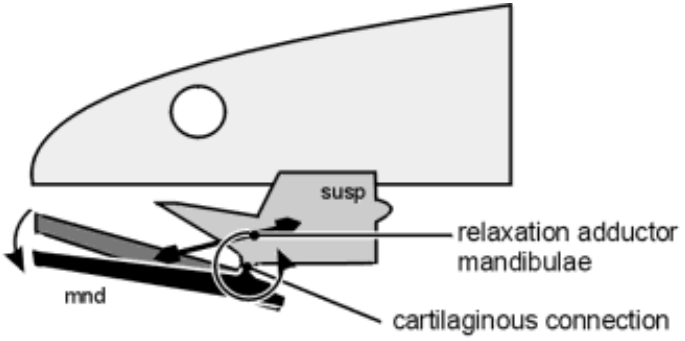

B

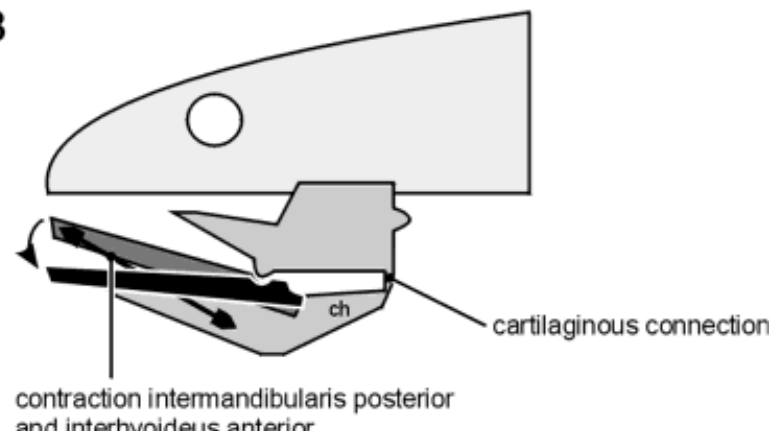

C and interhyoideus anterior
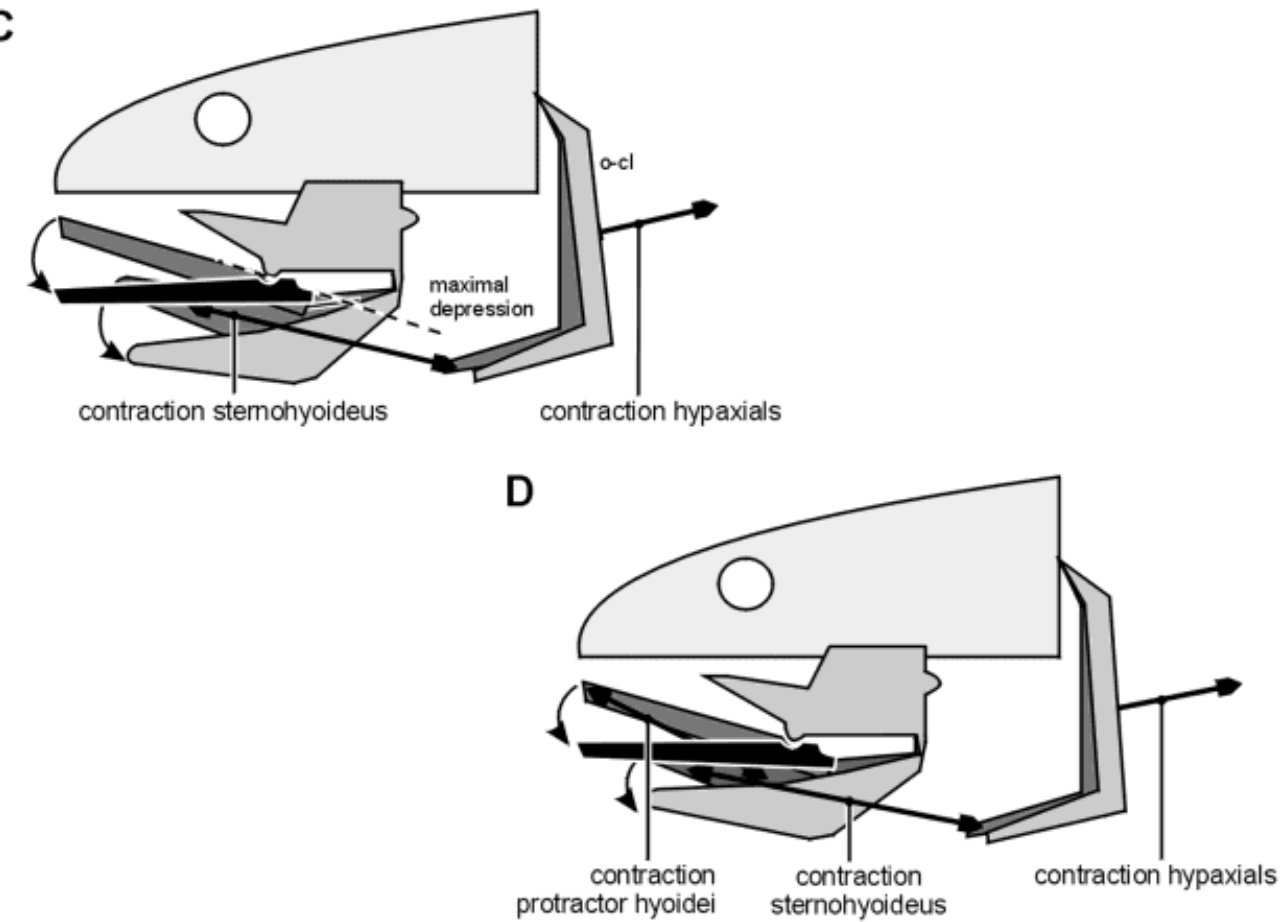

Fig. 2. Functioning of mouth opening mechanisms. A: Mechanism 1. B: Mechanism 2. C: Mechanism 3. D: Mechanism 4. E: Mechanism 5 (not drawn to scale). ch, ceratohyale; mnd, mandibula; o-cl, os cleithrum; o-op, os operculare; susp, suspensorium.

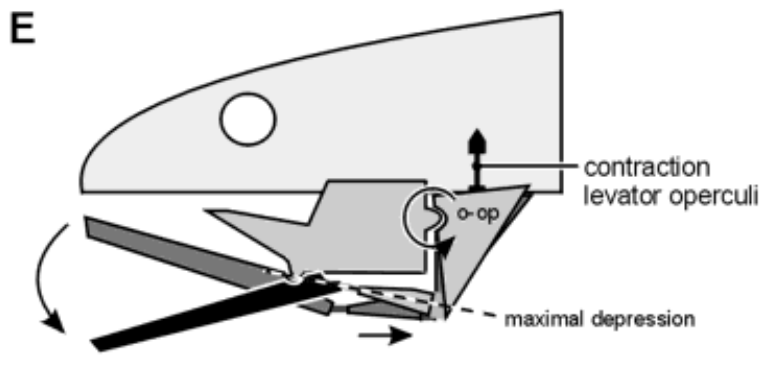

ticular process to which the mandibulo-hyoid ligament is attached. Later during ontogeny, this ligament becomes a stout connective tissue string, lying medial to the equally sized angulo-interopercular ligament. At $6.2 \mathrm{~mm}$ SL, the sternohyoideus muscle is connected to the hypohyal cartilage, as well as to 
the cleithral bone, and may thus become functional. In the juvenile stage, the sternohyoideus is a very large muscle, being especially broad posteriorly (Adriaens and Verraes, 1997b: fig. 8C). Rostrally this muscle inserts onto the forked parurohyal bone, which attaches through a short, paired ligament to the ventral hypohyal ossification (Adriaens and Verraes, 1998: fig. 4).

Function. From $6.2 \mathrm{~mm}$ SL on, mouth opening can now presumably occur more powerfully. The presence of the mandibulo-hyoid ligament (ligamentum angulo-ceratohyale of Adriaens and Verraes, 1997b) enables the coupling of hyoid depression during sternohyoideus activity to the jaw depression (Fig. 2C). This hyoid mouth opening mechanism works as a four-bar system (Fig. 3A). In this four-bar system the following constituents are present: 1 ) the frame, the bar between the mandibular articulation and the interhyal-suspensorium connection; 2) the crank, the bar between interhyal-suspensorium connection and insertion site of the mandibulo-hyoid ligament on the hyoid; 3) the coupler, the mandibulo-hyoid ligament; and 4) the follower, the bar between the mandibular articulation and the insertion site of the latter ligament on the retroarticular process. The depression of the hyoid bars can be observed in a $6.2 \mathrm{~mm}$ SL larva $(6.8 \mathrm{~mm}$ larva of Surlemont and Vandewalle, 1991). The maximal gape (about $40^{\circ}$ in the $7.2 \mathrm{~mm}$ SL stage) would be reached once the working line through the ligament reaches the mandibular articulation (Fig. 2C). In case neurocranial elevation would occur, this could speed up mouth opening, as well as make it more powerful. However, maximal gape would not be affected.

\section{Mechanism 4 (6.2 mm SL-...)}

Form. In the $6.2 \mathrm{~mm}$ SL stage, the intermandibularis posterior and interhyoideus anterior muscles can hardly be distinguished, as they have fused to form the protractor hyoidei (Fig. 1D). The latter muscle interconnects the rostral part of the lower jaw with the posterolateral part of the hyoid bars, as well as it embeds the mandibular barbel bases (Adriaens and Verraes, 1997b). The sternohyoideus forms the connection between the cleithral bone and the hyoid bars, whereas hypaxial muscles insert onto the posterior margin of the latter bone.

Function. According to this mechanism, the depression of the lower jaw would be coupled muscularly to the depression of the hyoid bars. In this case, the pectoral retraction (or fixation) through the contraction of the hypaxials, and the depression (or retraction) of the hyoid bars through the contraction of the sternohyoideus, could assist the mandibular depression through the contraction of the protractor hyoidei (Fig. 2D) (Osse, 1969), provided that its line of action is situated below the jaw suspension. The latter is the case in all stages of Clarias gariepinus
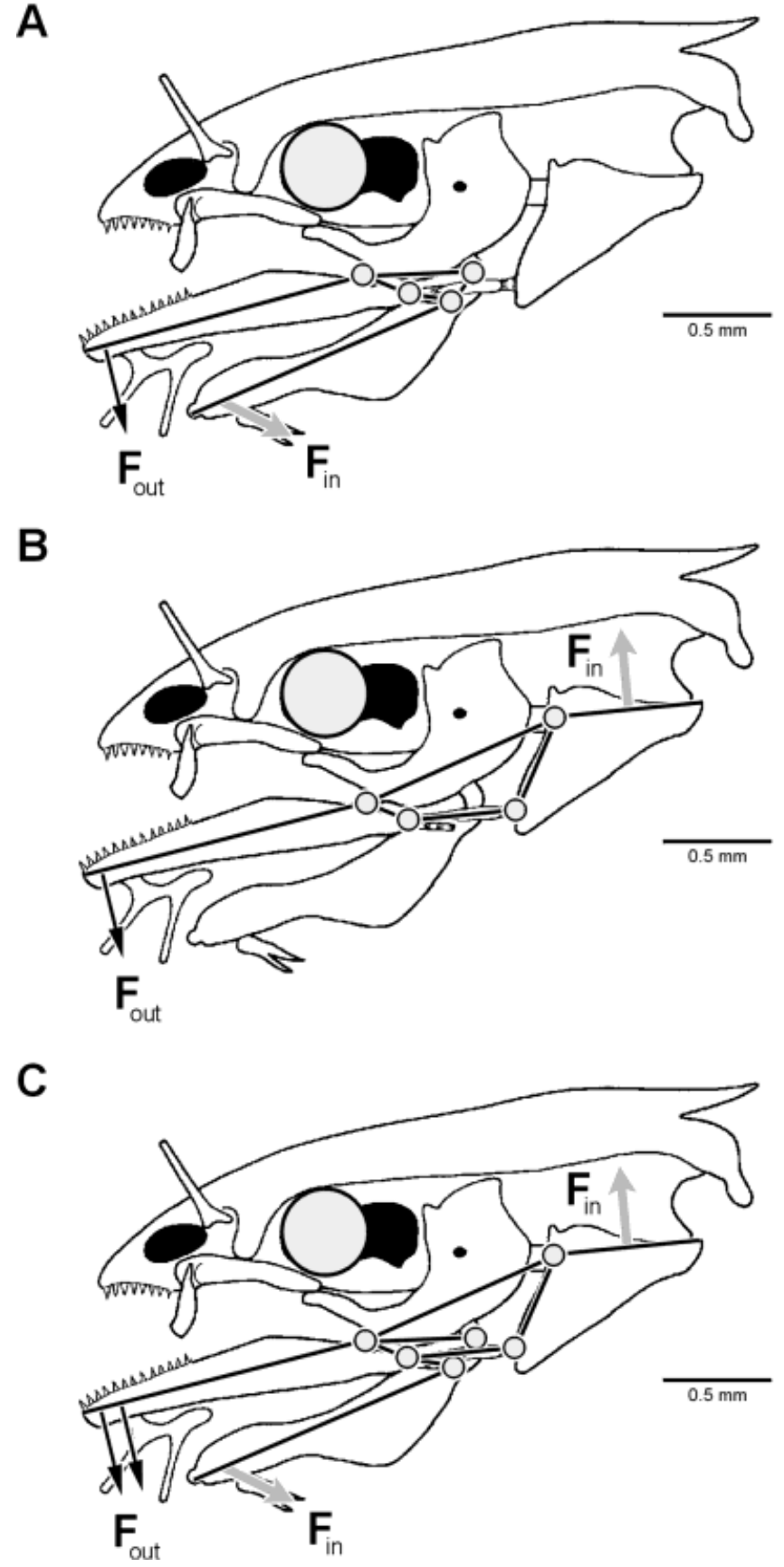

Fig. 3. Scheme of the hyoid and opercular four-bar systems in Clarias gariepinus. A: Hyoid system. B: Opercular system. C: Both systems transposed ( $\mathrm{F}_{\text {in }}$, input force, $\mathrm{F}_{\text {out }}$, output force).

(Fig. 5). Consequently, this mechanism could allow further mouth opening, once maximal gape is obtained in Mechanism 3.

\section{Mechanism 5 (11.1 mm SL-...)}

Form. At about $11 \mathrm{~mm}$ SL, the majority of cranial bones have formed in Clarias gariepinus (Adriaens and Verraes, 1998: fig. 25). The crucial, newly formed structures for this mouth opening mecha- 
nism involve the interopercular bone and the corresponding ligamentous connections with the lower jaw and the opercular bone. In the $11.1 \mathrm{~mm}$ SL larva, a rudimentary interopercular bone could be observed, with a ligamentous connection to both the retroarticular process and the opercular bone (in contrast to the observations of Vandewalle et al., 1985 , where this ligament was only observed at 21.5 mm SL) (Fig. 4A). The lower jaw now bears all its ossifications (with exception of the coronomeckelian bone). Later during ontogeny, the ligament becomes larger, whereas the retroarticular process bears a small process for its attachment (Adriaens and Verraes, 1998: fig. 20A). The levator operculi muscle may become functional in Clarias gariepinus at about $6.8 \mathrm{~mm}$ SL (Adriaens and Verraes, 1997b: table 1), whereas in juveniles it inserts on the complete dorsal margin of the opercular bone (Fig. 4B). The opercular bone is now tilted substantially (in a clockwise direction, for a lateral view of the left side), compared to the larval stages.

Function. The opercular four-bar system is a well-known mouth opening mechanism in teleosts (Aerts et al., 1985; Lauder and Liem, 1989). The input force is generated by the contraction of the opercular levator, making it rotate (Fig. 2E). The force is transmitted through the interopercular bone and both the ligaments attached to it, consequently pulling onto the retroarticular process of the lower jaw (Fig. 3B). The lower jaw is depressed, the maximum gape being reached once the axis through the interopercular bone and its ligaments runs through the mandibular articulation (about $35^{\circ}$ in the 19.1 $\mathrm{mm}$ SL stage). Based on the changes in the relative length of the four bars, ontogenetic changes in the efficiency of this mouth opening mechanism can be expected (Fig. 4) (see Discussion).

\section{Mouth Opening Efficiencies}

Mouth opening can only occur when the moments of the mouth opening muscles exceed that of counteracting forces, such as 1) the momentum of the water which has to be displaced, 2) the inertial forces of the accelerating jaw, 3) the negative pressure in the oral cavity, which is generated during mouth opening, and 4) the strain energy stored in mouth closing muscles that have relaxed (Aerts et al., 1987). It is thus of the utmost importance that mouth opening mechanisms are sufficiently efficient to overcome these forces.

In order to get any idea of the efficiency of mouth opening, calculating output velocities of the four-bar systems can provide some information. During ontogeny, the lengths of the bars, in relation to the frame, seem to change allometrically in Clarias gariepinus, which suggests a difference in efficiency. The ratio of the crank and follower appears to be higher in the opercular system, which would suggest that the opercular system is kinematically more efficient than the hyoid one. When taking into account the ratio of output and input lever lengths, the difference in output velocities will even be higher. The model supports these findings: 1 ) the output velocity of the hyoid system is larger in large juvenile stages, compared to larval stages; 2 ) the opercular system is kinematically more efficient than the hyoid system (Fig. 6). The efficiency of the opercular system in $C$. gariepinus, compared with that of some teleosts, shows that the output velocity of the opercular fourbar system in Clarias is substantially lower than that of the some other teleosts, and thus much more force efficient (Aerts and Verraes, 1984). The fact that the output force efficiency of the opercular fourbar system in Clarias is high does not imply that large forces will be generated on the lower jaw, as the size of the input force (from the levator operculi) is crucial as well. The question as to what degree the opercular four-bar system participates in generating the required mouth opening force remains unanswered (EMG studies are in progress).

The question can be raised as to what degree the hyoid and opercular four-bar systems contribute to the efficiency of mouth opening, and how this changes during ontogeny. The output velocity of the hyoid and opercular four-bar systems during mouth opening appears to show some kind of pattern, although the $19.0 \mathrm{~mm}$ SL stage does not always fit it. 1) The range of mandibular angles, during which the output velocity of the opercular system has not yet reached an arbitrary level of 50, increases during ontogeny (Fig. 7). The lowest range is observed in the $21.5 \mathrm{~mm}$ SL stage $\left( \pm 21^{\circ}\right)$, whereas in the 147.7 $\mathrm{mm}$ SL stage it reaches approximately $37^{\circ}$. The values for the hyoid system remain fairly constant between $25^{\circ}$ and $30^{\circ} .2$ ) The difference between output velocity values of the hyoid and opercular system is higher in early stages compared to later stages. The low levels of the hyoid output velocity suggest a higher output force, which is especially important since the input force in this four-bar system is much higher as well, compared to the opercular four-bar system. 3) During early ontogeny, the opercular output velocity reaches an arbitrary level of 50 equally as fast or even faster than the hyoid one. In later stages, the hyoid output velocity reaches that level more rapidly than does the opercular output velocity. Theoretically, it can be said that if input forces were equal the hyoid four-bar system would be more important for generating a powerful mouth opening, especially during early ontogeny, whereas the opercular system would enable a fast mouth opening. However, this would be a simplification to a large degree, as 1) input forces differ largely (small levator operculi and large sternohyoideus), and 2) both mechanisms will act and interact in a more complex manner (Fig. 3C). 

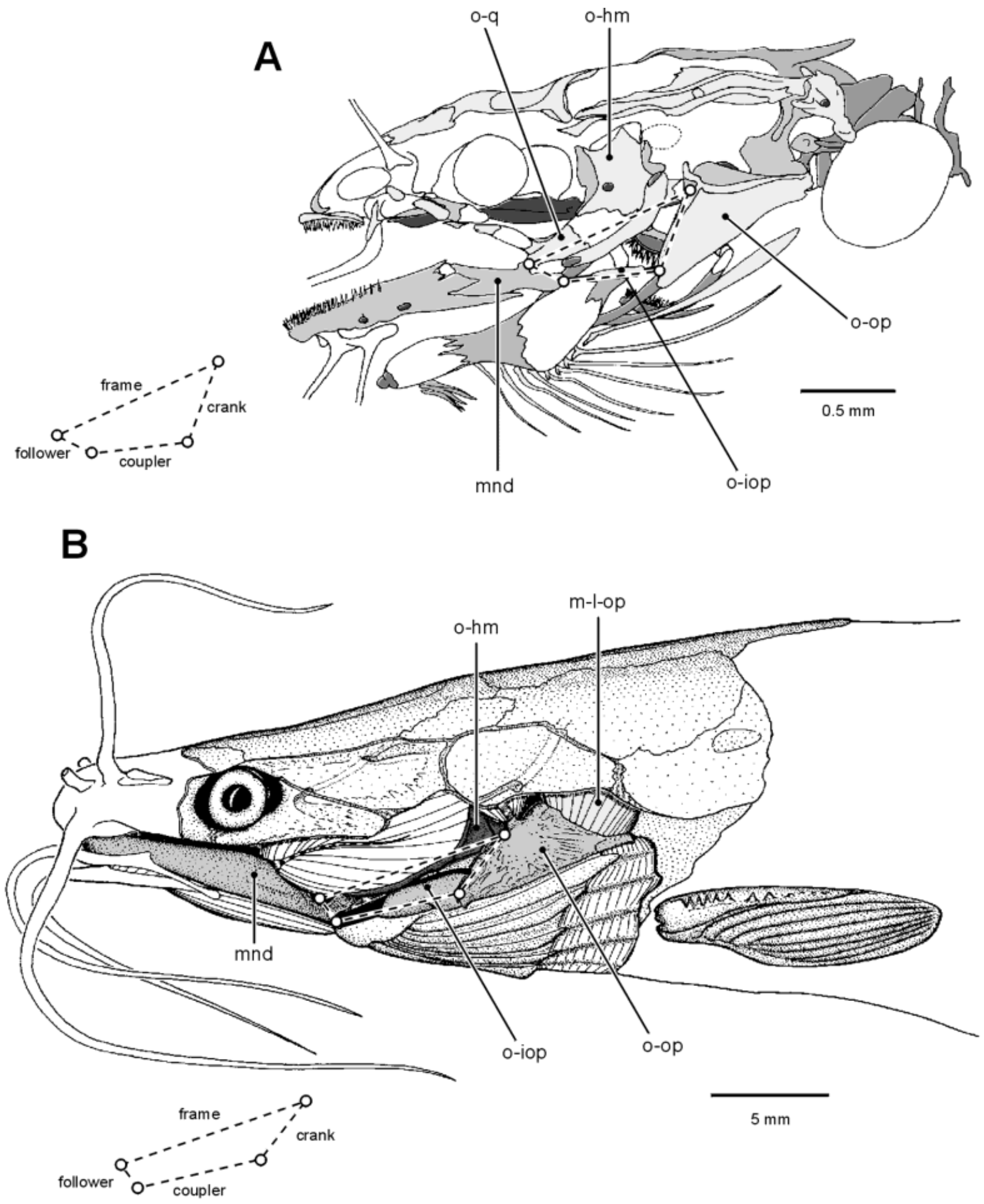

Fig. 4. Opercular four-bar system (Mechanism 5) in Clarias gariepinus.. A: 11.6 mm SL stage. B: 125.5 mm SL. m-l-op, musculus levator operculi; mnd, mandibula; o-hm, os hyomandibulare; o-iop, os interoperculare; o-op, os operculare; o-q, os quadratum. 


\section{working line below jaw articulation}

\section{working line above jaw articulation}

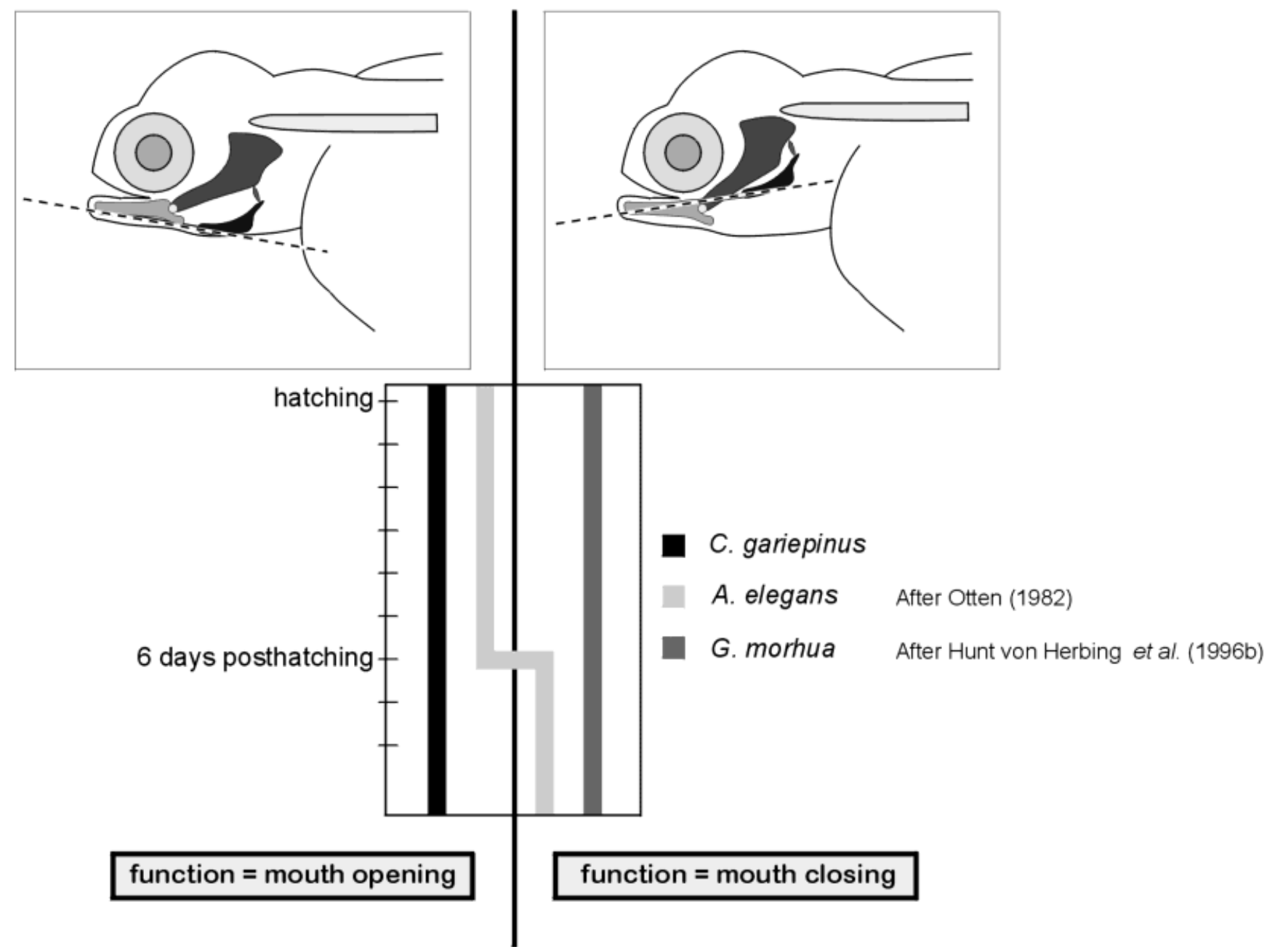

Fig. 5. Scheme of the functional shift of the protractor hyoidei.

\section{DISCUSSION \\ Ontogenetic Shift in Mouth Opening Mechanisms}

Mouth opening in teleosts is established through a wide range of mechanisms, from very simple ones to a whole complex of integrated couplings. Simple mechanisms involve the coupling of hyoid depression to mandibular depression (Otten, 1982; De La Hoz and Aldunate, 1994; Hunt von Herbing et al., 1996a). Mouth opening becomes more complex once four-bar systems are involved (Anker, 1974; Aerts and Verraes, 1984; Westneat, 1990, 1994). More complex mouth opening mechanisms involve the coupling of the mandibular depression to a whole set of other mechanisms: neurocranial elevation (Muller, 1987), intracranial angulation (Lauder, 1980b), maxillary rotation (Aerts and Verraes, 1987; Westneat and Wainwright, 1989; Westneat, 1990), premaxillary protrusion (Westneat and Wainwright,
1989; Westneat, 1990), and even lower jaw protrusion (Westneat and Wainwright, 1989).

As the complexity of a mechanism can be related to the number of elements involved, it can be expected that the complexity of mouth opening mechanisms may increase during ontogeny. This implies that an ontogenetic shift in mouth opening mechanisms is not unfavorable in order to constantly optimize mouth opening (in relation to the apparatus present). Such a shift appears to be present in Clarias gariepinus, where an increase in complexity is apparent (Fig. 8). Ontogenetic shifts in mouth opening mechanisms have been noted in other fishes as well (Verraes, 1977; Otten, 1982; Liem, 1991; Hunt von Herbing et al., 1996a; Hunt von Herbing, 1997). In general, two types of mouth opening mechanisms are distinguished in teleosts: 1) a hyoid mouth opening mechanism, and 2) an opercular mouth opening mechanism. Passive mouth opening has been introduced by Surlemont et al. (1989). 

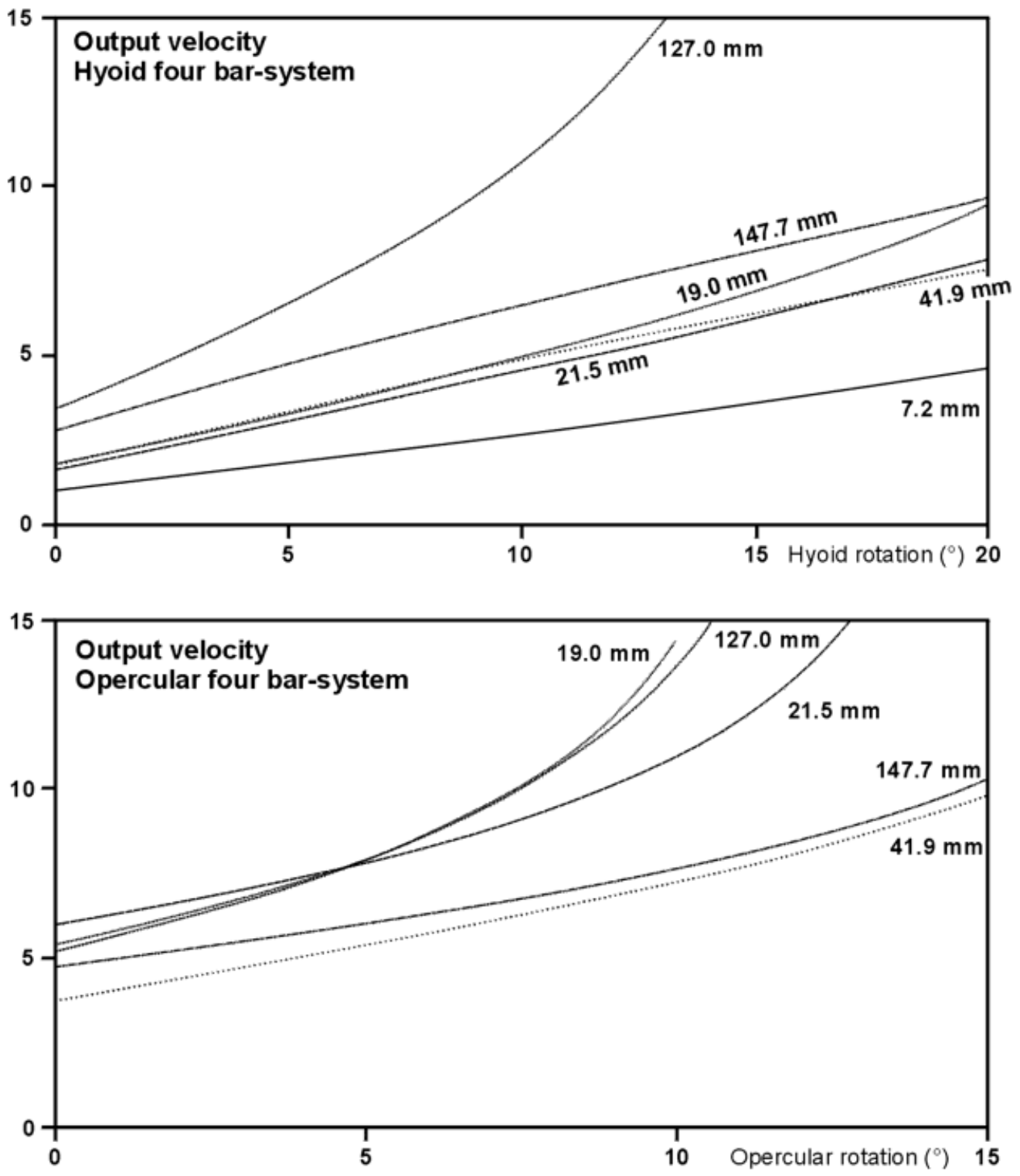

Fig. 6. Output velocity of the hyoid and opercular fourbar system during ontogeny in Clarias gariepinus.

\section{Passive Mouth Opening Mechanisms}

The presence of passive mouth opening mechanisms has generally been overlooked, as it presumably only plays a crucial role in early life stages, if present. In the case of Clarias gariepinus, Surlemont et al. (1989) emphasized the importance of the cartilaginous connection between the lower jaw and the suspensorium in mouth opening. However, as muscular action cannot be excluded at this stage, the importance of passive mouth opening should not be overrated. It may play a supportive role in mouth opening, as at this stage the muscles are very rudimentary. A study on the contraction capacities of such primordial muscle tissue could provide some information on the necessity for such a passive mouth opening mechanism during early ontogeny.

If, indeed, as suggested by Surlemont et al. (1989), muscle contraction of the ventral muscles cannot induce mouth opening, this passive mechanism does play a crucial role, but only until a true articulatory facet is formed on the lower jaw. Although feeding still occurs endogenously at this stage, respiratory requirements for buccal ventilation may increase.

\section{Hyoid Mechanisms}

The hyoid mechanism involves the ligamentous coupling of hyoid depression to mouth opening. Although the presence of such a mandibulo-hyoid ligament in teleosts has been linked to lower jaw length (Verraes, 1977), its presence appears to be a plesiomorphic feature of non-ctenosquamate teleosts, as well as lower Actinopterygii (Lauder, 1980a; Johnson, 1992; Stiassny, 1996). In aulopiform fishes, this ligament becomes extended posteriorly, thus inserting onto the interopercular bone, 

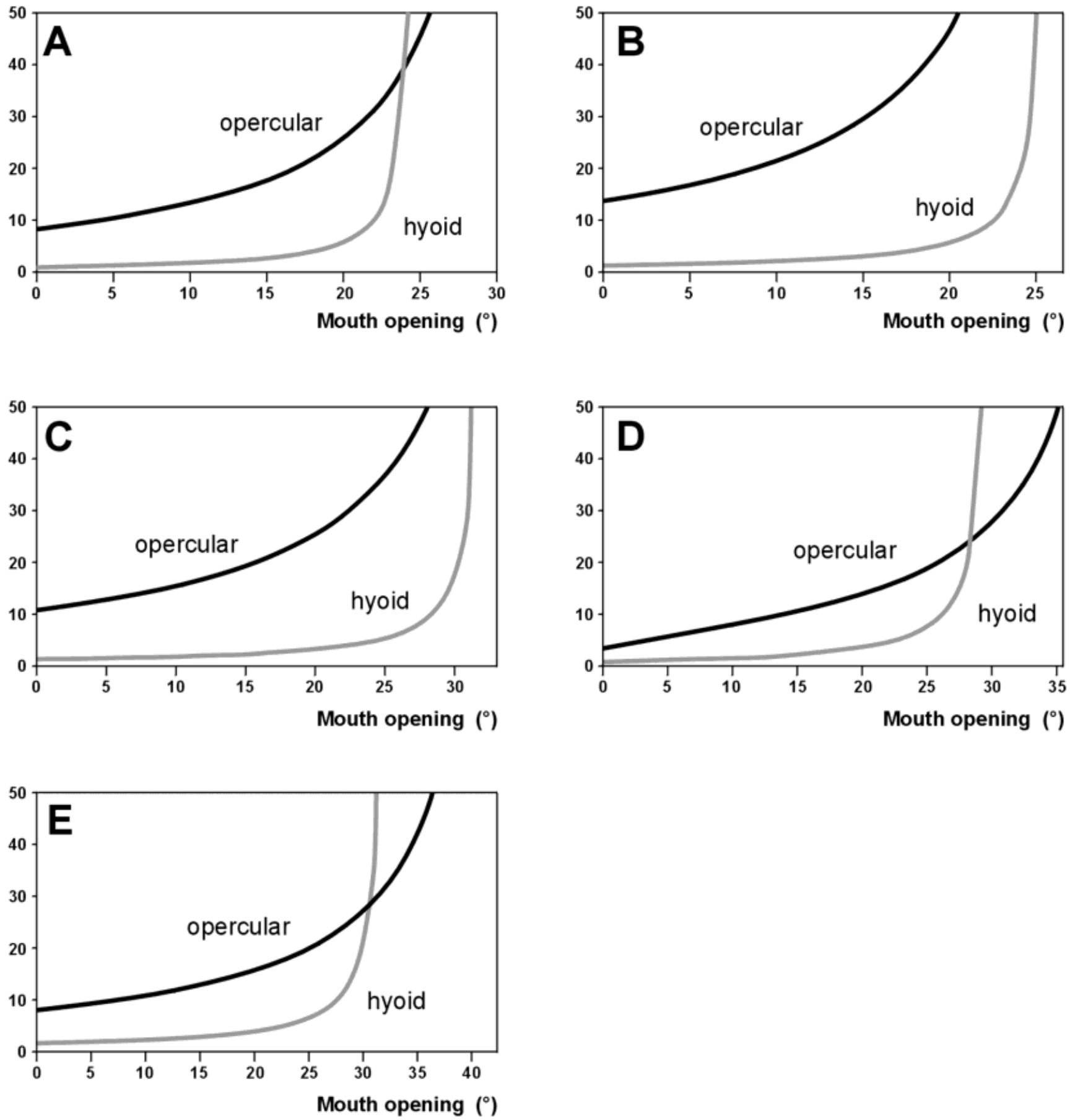

Fig. 7. Output velocities of hyoid and opercular four-bar systems during mouth opening in Clarias gariepinus. A: 19.0 mm SL. B: $21.5 \mathrm{~mm}$ SL. C: $41.9 \mathrm{~mm}$ SL. D: $127.0 \mathrm{~mm}$ SL. E: 147.7 mm SL.

whereas in Ctenosquamata the connection with the lower jaw is lost. In several non-ctenosquamate teleosts, the ligament can be observed early during ontogeny: Clarias gariepinus, Oncorhynchus mykiss Walbaum, 1792, and Gadus morhua (Verraes, 1977; Hunt von Herbing et al., 1996a; Adriaens and Verraes, 1997b).
As mentioned in Results, the role of the protractor hyoidei as a mouth opener also depends on the position of its line of action in relation to the mandibular joint (Otten, 1982) (Fig. 5). If ventral to this joint, the protractor will enable mouth opening. However, once dorsal to the articulation the function of the muscle shifts from mouth opening to mouth 


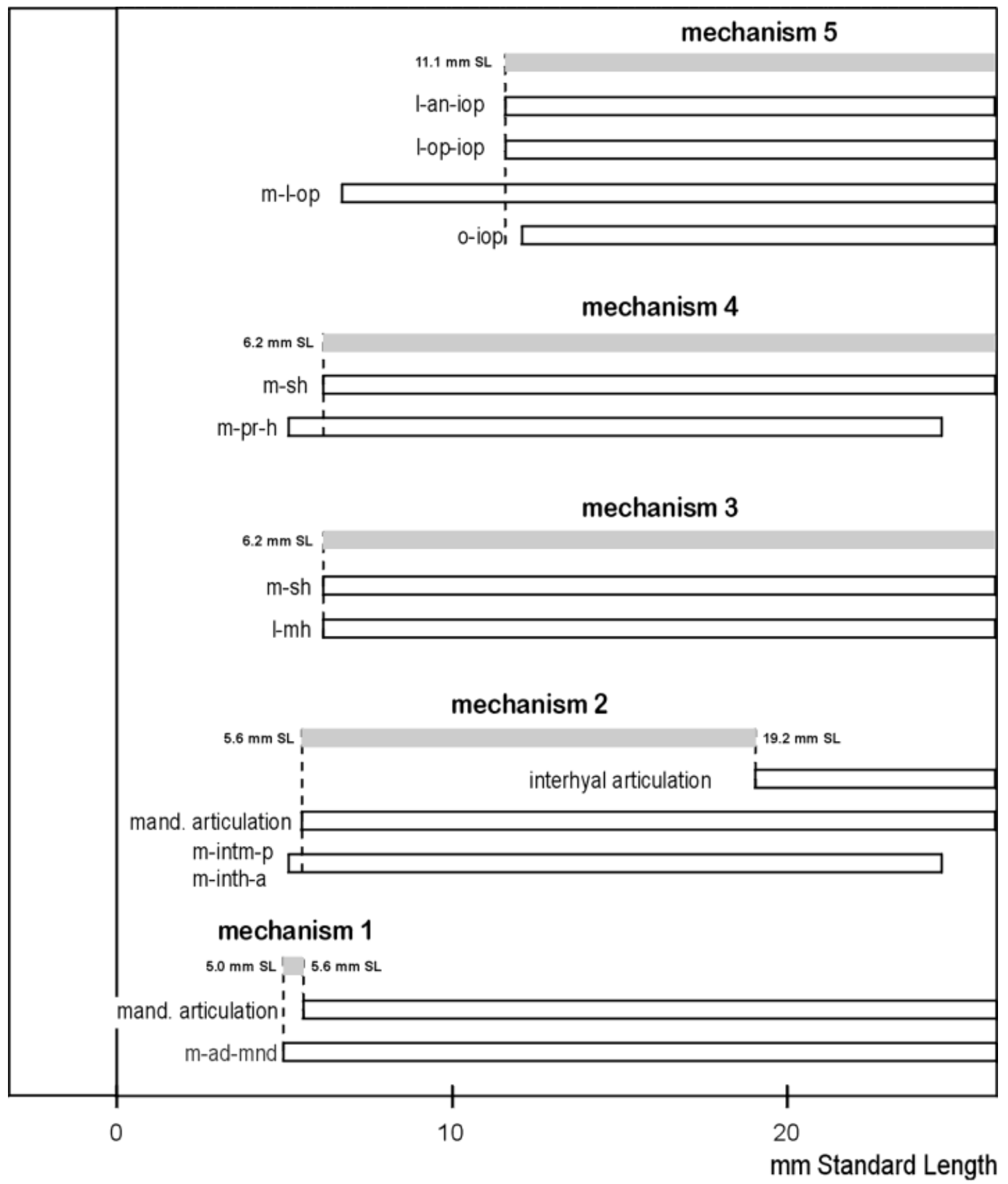

Fig. 8. Overview of the morphological features, with corresponding mouth opening mechanisms in Clarias gariepinus. l-an-iop, ligamentum angulo-interoperculare; l-mh, ligamentum mandibulo-hyoideum; l-op-iop, ligamentum operculo-interoperculare; m-admnd, musculus adductor mandibulae complex; m-inth-a, musculus interhyoideus anterior; m-intm-p, musculus intermandibularis posterior; m-l-op, musculus levator operculi; m-pr-h, musculus protractor hyoidei; m-sh, musculus sternohyoideus; o-iop, os interoperculare.

closing, as observed in a cichlid species (Fig. 5) (Anker, 1974; Elshoud-Oldenhave and Osse, 1976). Such shifts are also observed in Pomacentridae and Embiotocidae, whereas in the latter the shift occurs during the intraovarian life stage (Liem, 1991). As in cod the protractor hyoidei remains a mouth closer, the presence of a mandibulo-hyoid ligament is crucial for mouth opening during early life stages (Hunt von Herbing et al., 1996a). In Clarias gariepinus the protractor remains a mouth opener during the entire ontogenetic period, which means that, theoretically, both the ligamentous and the muscular hyoid mouth opening mechanisms could generate mouth opening. Supportive evidence comes from 


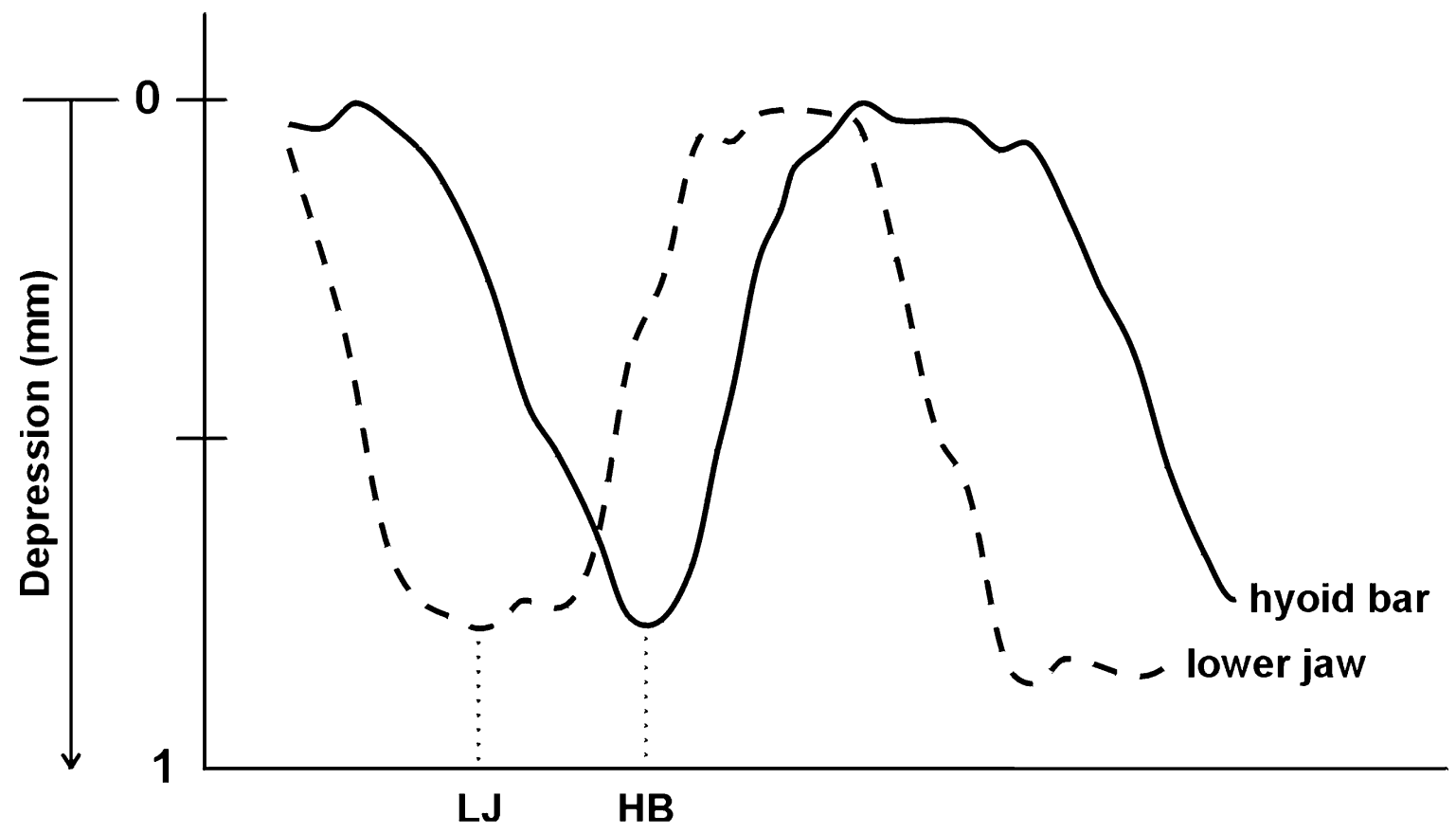

Fig. 9. Kinematics of mandibular and hyoid depression in larval Clarias gariepinus $(6.2 \mathrm{~mm}$ SL), showing the time lapse between the onset of both depression movements. LJ, lower jaw; HB, hyoid bar. (Modified from Surlemont and Vandewalle, 1991.)

the ontogenetic change in the quadrate angle (as depicted in the inset of Fig. 10). This angle gives an indication of the ventral and anterior displacement of the mandibular joint during ontogeny (large angles assume a mandibular joint below the protractor working line) (Otten, 1982; Hunt von Herbing et al., 1996a). In Astatotilapia elegans (Trewavas, 1933), this angle increases rapidly (up to $90^{\circ}$ ), where at the 6 days critical period the angle increases to a much lesser degree when the protractor becomes a mouth closer (Fig. 5). A large quadrate angle (up to about $160^{\circ}$ ) is observed during the entire ontogenetic period in Gadus, whereas in Clarias and Oncorhynchus the angles remain fairly low. The dorsoventrally flattening of the skull can partially explain the low values of quadrate angles in $C$. gariepinus. Some trends can be observed: 1) low quadrate angles are observed at the moment the yolk sac is resorbed (except for Astatotilapia); 2) maximal quadrate angles are obtained at the moment the opercular fourbar system becomes functional (except for Astatotilapia and Micrometrus). This may suggest that the muscular hyoid apparatus may play an important role in mouth opening during early ontogeny, especially for respiratory purposes, whereas mouth opening for feeding requires the involvement of other mechanisms.

Kinematically, both hyoid mechanisms (i.e., the ligamentous and muscular) can hardly be distinguished from each other. However, it has been suggested that the ligamentous hyoid mechanism involves a simultaneous depression of the hyoid bar and the lower jaw (Hunt von Herbing et al., 1996a), whereas in the muscular hyoid mechanism the hyoid depression follows the mandibular one shortly after (Otten, 1982). Data from EMG support this idea (Lauder, 1980a). In $6.2 \mathrm{~mm}$ SL larvae, the hyoid depression was observed to initiate shortly after the mandibular depression, which might indicate that the muscular hyoid mechanism is responsible for mouth opening (Fig. 9) (Surlemont and Vandewalle, 1991). This, however, brings up the question concerning the functioning of the mandibulo-hyoid ligament (see below).

The synchronous action of neurocranial elevation during mouth opening has been observed in several teleosts (e.g., Osse, 1969; Lauder, 1979; Muller, 1987). However, in Clarias, as well as in catfishes in general, the highly modified Weberian apparatus becomes increasingly large and broad during ontogeny, as well as the vertebrae of the complex becoming fused to each other (Radermaker et al., 1989). Consequently, the spatial constraints of the nuchal area may restrict the effect of neurocranial elevation. However, this would only imply that the rotation point becomes shifted backward, between the vertebral complex and the sixth vertebra. As observed in cichlids, neurocranial elevation is not restricted to a focused rotation point between two vertebrae, but rather a bending of the anterior part of the vertebral column (Aerts, 1987). A supraoccipital crest, which is generally associated with improved neurocranial elevation, is absent in Clarias. However, at the ventral side of the parieto-supraoccipital 
$\left.\alpha{ }^{\circ}\right)$

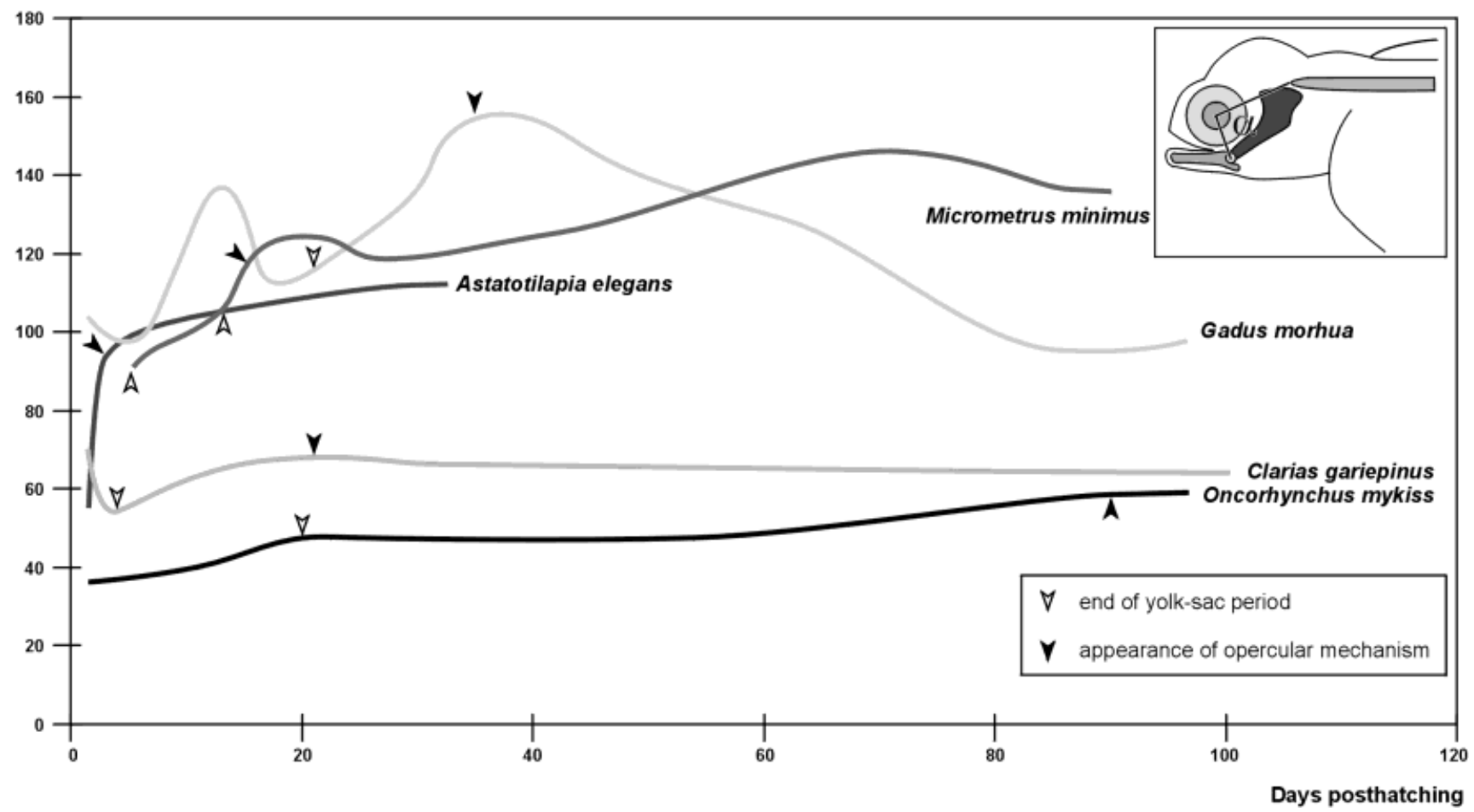

Fig. 10. Graph of the quadrate angle during ontogeny in five teleosts (data based on Otten, 1982; Hunt von Herbing et al., 1996a, Liem, 1991).

bone complex, a large vertical crest is present, connected to the Weberian apparatus (Adriaens and Verraes, 1998: fig. 16). This crest provides a good alternative for an enlarged insertion surface and lever action for the epaxial muscles, fitting into the design of the dorsoventrally flattened skull. Neurocranial elevation has been observed during feeding in Ictalurus (Ictaluridae) (Alexander, 1970).

\section{Opercular Mechanisms}

The opercular mechanism is observed in most adult teleosts, where it functionally replaces or assists the hyoid mouth opening mechanism (Anker, 1974; Lauder, 1982; Otten, 1982; Lauder and Liem, 1989; Liem, 1991; De La Hoz and Aldunate, 1994). The contraction of the levator operculi during mouth opening has been demonstrated by numerous electromyographic studies (Osse, 1969; Elshoud, 1978; Lauder and Liem, 1980; Lauder, 1981; Liem, 1984; Wainwright and Turingan, 1993). In some teleosts (e.g., Cichlidae, Pomacentridae), the opercular mechanism becomes functional synchronously with the functional shift of the protractor hyoidei from mouth opening to mouth closing (Otten, 1982; Liem, 1991) (Figs. 5, 10). In these teleosts, the synchronization of this shift in mouth opening mechanisms is thus crucial for their survival. The shift from the hyoid mechanism to the opercular mechanism occurs very early during ontogeny in those species that lack a mandibulo-hyoid ligament (after 6\% of the larval period) (Hunt von Herbing et al., 1996a). In general, the opercular mechanism becomes functional after the yolk sac has been resorbed (Fig. 10), which may suggest that the shift may be related to an ontogenetic shift in feeding behavior (see below). Cichlids seem to differ from this general trend, which can be explained by the fact that very early during ontogeny (i.e., during the yolk sac stage) both the ligamentous and muscular hyoid mechanisms cannot function (both the mandibulo-hyoid and hyoid-interopercular ligaments are missing and the protractor hyoidei is a mouth closer, respectively). The functioning of the opercular mechanism is thus crucial. In Embiotocidae such an acute shift is present as well: the opercular system becomes functional at the moment the protractor becomes a mouth closer (the ligamentous hyoid system cannot function due to the absence of the ligament), although well after the yolk sac has been resorbed (Fig. 10).

Although in some teleosts an acute shift occurs from one mouth opening mechanism to another, several examples can be given in which a clear overlap occurs (Lauder and Liem, 1989), including Clarias gariepinus (Figs. 8, 11). Between 6.2 and $11.1 \mathrm{~mm}$ 


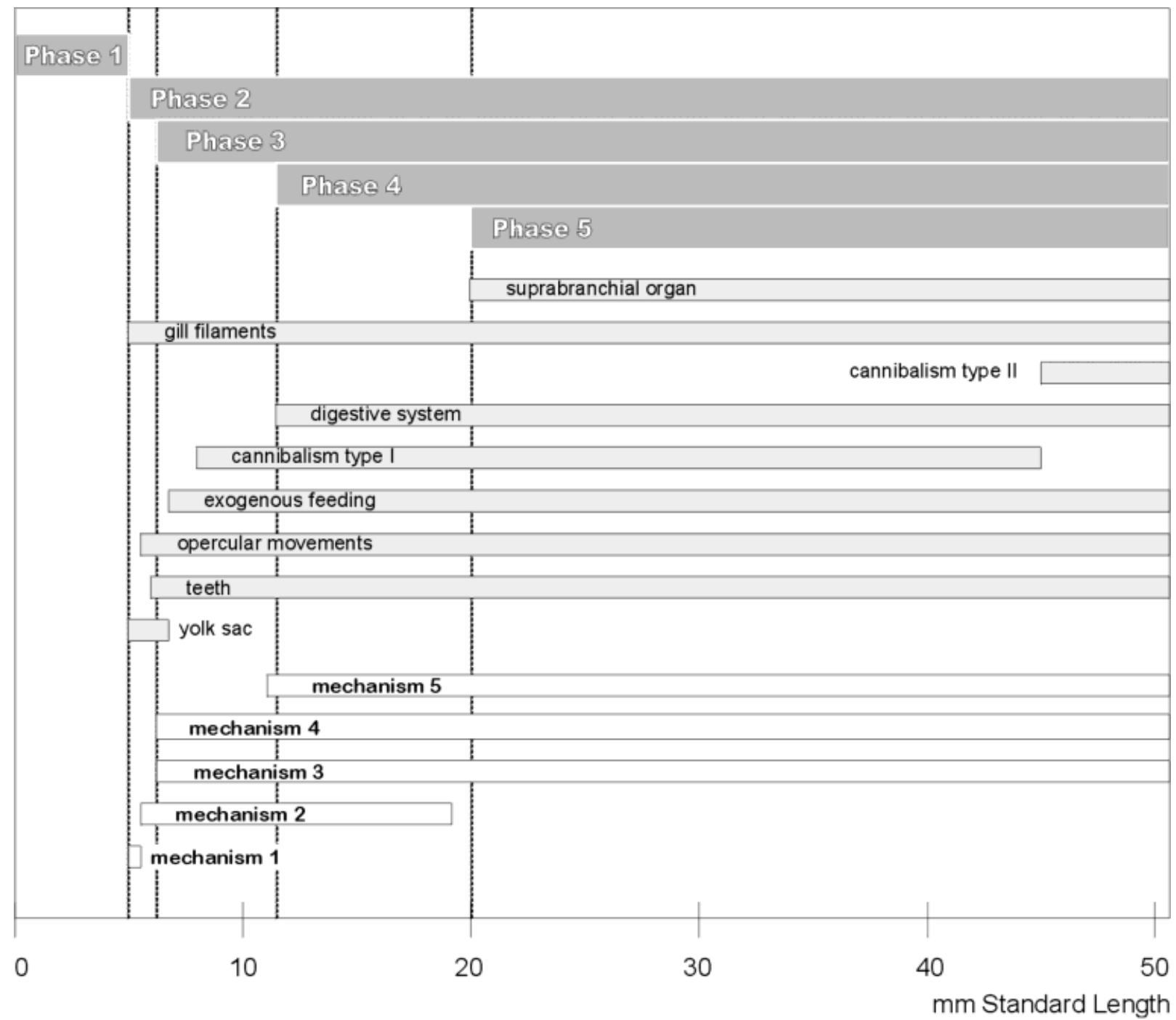

Fig. 11. Overview of the ontogenetic shift in mouth opening mechanisms in relation to functional demands: Phase 1 = passive, aquatic, cutaneous respiration; Phase $2=$ active, aquatic, gill respiration; Phase $3=$ active (exogenous) feeding; Phase $4=$ carnivory; Phase $5=$ aerial respiration.

SL, both hyoid mouth opening mechanisms (Mechanisms 3 and 4) may be functional (the effect of the cartilaginous interhyal in Mechanism 2 is neglected here). From $11.1 \mathrm{~mm}$ SL on, the opercular mechanism may become functional as well, thus leaving three mechanisms that can enable mouth opening at the same moment. An overlap of mechanisms becomes advantageous if protagonism exists, with a chronological shift of their specific efficiency peaks during the process of mouth opening, as suggested from the model: during the earlier stages the opercular mechanism appears to be velocity-efficient, whereas the hyoid mechanism appears to be more force-efficient (Fig. 7). Opercular rotation coupled to mandibular depression has frequently been observed; however, maximal gape is not always reached when the opercular rotation is maximal
(Westneat, 1990). This suggests that the opercular mouth opening mechanism is only functional during a certain phase of mouth opening, and in order to obtain a maximal gape another mechanism has to take over. It has been suggested in cichlids that the role of the opercular mouth opening mechanism during feeding involves the triggering of mouth opening, whereas the mandibular depression is exerted by the contraction of the hyoid musculature (Lauder, 1981; Aerts et al., 1987). Ontogenetically protagonist mechanisms may thus chronologically be protagonists as well, meaning that they may assist each other during mouth opening in keeping up the required efficiency at all levels of mouth gape (see below).

Overlap of mechanisms may also allow a shift in function in one of the mechanisms (Lauder et al., 
1989; Lauder and Liem, 1989). It may thus well be that the simultaneous action of the muscular and ligamentous hyoid mechanisms has allowed the differentiation of the protractor hyoidei in a superficial part controlling the mandibular barbels, and a deeper part, which presumably still assists in mouth opening (Ghiot et al., 1984; Adriaens and Verraes, 1997b). This would suggest that the ligamentous mouth opening mechanism would be of greater importance compared to the muscular system, thus contradicting what has previously been said. However, to clarify this an electromyographical analysis of larval Clarias gariepinus mouth opening would be required in order to determine to what degree the protractor hyoidei assists in mouth opening. An overlap of mouth opening mechanisms may have enabled the structural innovations observed in Loricariidae and Astroblepidae, where the connection between the lower jaw and the opercular bone is lost (Schaefer, 1987; Schaefer and Lauder, 1996).

\section{Ontogenetic Shift in Feeding Behavior}

During ontogeny, fishes increase their prey capture success. Consequently, mouth opening may have to be improved in order to occur faster (Coughlin, 1994; Cook, 1996). As it has been estimated that a prey size of 0.6 times a fish mouth size gives the greatest energetic benefit in relation to time cost, the gape size will be important also (Gill, 1997). Changes in feeding mode generally involve changes in ram- or suction-actions during feeding, which are the result of ontogenetic alterations in morphology and behavior (Cook, 1996). In Lates calcarifer (Centropomidae), the capture efficiency in early larvae (i.e., $10-20 \mathrm{~h}$ posthatching) largely depends on the size of the larvae, whereas in older larvae (i.e., $60-70 \mathrm{~h}$ posthatching) the feeding ability is greatly improved by the ontogenetic differentiations of the skull. At that stage, structures have formed that allow suction/grasping and manipulation of prey, whereas earlier prey capturing is dependent on suction abilities only (Kohno et al., 1996b). Because of the fact that fishes live in "an environment with a density 800 times and viscosity 30 times that of air," they require a highly effective mechanism for prey capture (Osse, 1990). This could be done by producing a high forward thrust and some suction feeding in order to engulf prey, or by producing a high suction force. However, as Osse (1990) stated, that when "larvae start external feeding, their suction forces must be high because little contribution of swimming and none of protrusion is available," many fish larvae start as suction feeders (Osse, 1990; Kohno et al., 1996a). In carp larvae of $6.5 \mathrm{~mm}$, a negative pressure inside the orobranchial cavity has been estimated to reach $-300 \mathrm{~Pa}$ (Drost et al., 1988). Suction feeding has been observed in other teleostean larvae (Coughlin, 1994), although more straining-like feeding types have been suggested as well (Kohno et al., 1996a).

One crucial factor for suction feeding is the presence of an opercular cover (Osse, 1990). This implies that, for cod, suction feeding would only be possible after 3-4 weeks posthatching (about $6 \mathrm{~mm}$ larvae), as the opercular bone fails to develop until then (Hunt von Herbing et al., 1996b). In Clarias gariepinus, the opercular bone is the first bone to develop (formation starts at about $4.1 \mathrm{~mm}$ SL, 1 day posthatching). Initial orobranchial expansions are theoretically possible from $5.0 \mathrm{~mm}$ SL on (Surlemont et al., 1989). These involve the abduction of the suspensoria, the elevation of the neurocranium, and the depression of the lower jaw (Adriaens and Verraes, 1997d: table 1). Functional teeth are observed shortly after (at about $6.0 \mathrm{~mm}$ SL). At that stage, however, larvae still possess a yolk sac, implying that active feeding may not be crucial yet. It may be possible that suction action at that time is mainly for respiratory purposes.

The application of the model of de Visser and Barel (1996) to the data of Clarias gariepinus suggested that in early larval stages the sternohyoideus contraction will generate substantial hyoid depression but little suspensorial abduction, with a gradual shift to increasing suspensorial abduction during later ontogeny. The reduction of hyoid depression in juvenile stages could be related to the dorsoventral flattening of the skull. In a way, it could explain the ontogenetic shift from a cartilaginous connection to a ligamentous connection between the suspensorium and the interhyal: the action onto the hyoid bar can consequently be restricted to a retraction instead of a substantial depression (Adriaens and Verraes, 1994). The reduction of substantial hyoid depression in juvenile $C$. gariepinus fits into the previously formulated hypothesis that such a depression is not required and would even be disadvantageous for dorsoventrally flattened species, like $C$. gariepinus (Adriaens and Verraes, 1994, 1997e). Its major role may then be for mouth opening, as it pulls on the lower jaw when retracted. However, true evidence to support or invalidate this hypothesis has to come from kinematic analysis (in progress). A sternohyoideus below the horizontal hyoid plane and low d $\alpha$-values, as well as feeding behavior (Hecht and Appelbaum, 1987), suggest that during early stages $C$. gariepinus larvae perform a suction/grasping way of feeding, whereas later juvenile stages are piscivore biters. This can also be derived from the overall skull morphology. Suction feeding is improved if the skull changes from tube-like to cone-like, implying pointed snouts and high heads (Alexander, 1965, 1967; Muller and Osse, 1984; Hunt von Herbing et al., 1996a). In $C$. gariepinus, skull morphology approaches this situation more closely during early stages than in juvenile stages, where in the latter the skull and the mouth are broad and flat. This does not, however, 
imply that juvenile and adult $C$. gariepinus cannot perform any suction. Minute suction forces have been demonstrated in ictalurids, which also have dorsoventrally flattened heads, although not to such a great extent. Broad skull bases also imply that minute hyoid depressions can generate larger volume expansions (Adriaens and Verraes, 1997e). The fact that $C$. gariepinus shows cannibalistic behavior from $8 \mathrm{~mm}$ SL on implies that feeding cannot depend on suction only, and that grasping is equally or even more important. Feeding on prey of about the same size as the predator would require enormous suction forces if feeding occurred by suction only.

The presence of numerous gill rakers in the juvenile and adult Clarias gariepinus may be a reflection of an opportunistic feeding behavior rather than an adaptation to a restricted filter feeding.

\section{Ontogenetic Shift in Functional Demands}

It can be predicted that the survival of fish larvae would be enhanced if the shift in mouth opening mechanisms and the shift in feeding types would be coupled to the shift in functional demands with which the developing larva has to deal. As mentioned above, an ontogenetic shift in diet is present in most teleosts, as a response to increasing nutritional demands. As observed in some cichlids, the timing of the shift between two mechanisms can be so acute that within 1 day the larva is doomed to die of starvation or to be able to feed (Otten, 1982). It would, however, be advantageous that a safety factor became incorporated in order to reduce such vulnerable moments during ontogeny (Galis et al., 1994). This can be done in different ways: 1) the elements of a certain apparatus can be formed prior to the moment that the involved mechanism and function is needed, or 2) the functioning of different mechanisms can overlap chronologically: when one mechanism becomes inoperative, the functional demand can still be dealt with by the other. For example, although functional demands for feeding and respiration are absent in viviparous embiotocids (feeding is intraovarian, whereas respiration occurs through enlarged and highly vascularized median fins), a synchronous shift occurs when the protractor hyoidei becomes a mouth closer and the opercular mouth opening mechanism becomes functional (Liem, 1991). In this case, a new reproductive strategy reduces the chances of mortality because of possible asynchronies between ontogenetic functional shifts of cranial elements.

Mouth opening will be important for feeding and respiratory movements during ontogeny. In this study, we attempted to investigate to what extent a relationship can be found between the timing of the different mouth opening mechanisms during ontogeny and some morphological, behavioral, or physiological changes related to nutritional or respiratory demands (Fig. 11). Based on these data, five main phases can be recognized in the life history of Clarias gariepinus.

Phase 1 (0-5.0 mm SL). Initially, at hatching no mouth opening is possible. Respiration must occur through cutaneous diffusion, as no sign of gills is observed. A so-called hyoidean vascular net may function as a respiratory organ (Greenwood, 1955). The ventilation of the boundary layer of water, surrounding the larva, occurs through undulatory movements of the notochord, which results in forward locomotion. Nutrition is completely dependent on the yolk sac (Hecht and Appelbaum, 1987; Kamler et al., 1994).

Phase 2 (5.0-6.2 mm SL). The first movements of the lower jaw are observed: mouth closing occurs through contraction of the adductor mandibulae, whereas Mechanism 1 and subsequently Mechanism 2 can allow mouth opening. Consequently, the first volume changes of the buccal cavity may occur. At this moment the gill filaments have started to form, indicating a possible respiratory shift. The formation of the opercular cover, as well as its initial movements, may take part in the initial respiratory pumping mechanism. As the yolk sac is still substantial at this stage, the movements of the mouth presumably are mainly for respiratory purposes. However, this phase spreads close to the end of the yolk sac period, indicating that active feeding will become necessary at the end of this phase. This yolk sac phase also allows a learning process, in order to improve mouth opening and prey capture (Coughlin, 1994).

Phase 3 (6.2-11.5 mm SL). This phase starts at the transition from endogenous to exogenous feeding. As the yolk sac period is terminating, adaptations to active feeding become essential. The onset of this phase is characterized by the formation of the hyoid mouth opening mechanisms (Mechanisms 3 and 4) (6.2 $\mathrm{mm}$ SL). At this stage, teeth have formed, indicating the potential for prey capture. At 3 days of age posthatching (6.5-7.0 mm SL), oxygen consumption reaches a maximal peak for yolk sac larvae of Clarias gariepinus raised at $25^{\circ} \mathrm{C}$ (Kamler et al., 1994). Respiratory requirements will consequently become more important. At $8 \mathrm{~mm}$ length, $C$. gariepinus larvae in captivity show a cannibalistic behavior, which implies the ability to capture and engulf large prey items (in the natural habitat this would mean other small fish species), as well as to generate large biting forces (cannibalism type I of Hecht and Appelbaum, 1987, 1988). This indicates that extensive mouth opening is essential and that a powerful adductor mandibulae is needed. At the end of this phase the opercular mouth opening mechanism may become functional, presumably as a preparation to fully carnivorous feeding behavior.

Phase 4 (11.5-20 mm SL). This phase is characterized by the digestive system, which now becomes completely functional. At $11.5 \mathrm{~mm} \mathrm{SL}$, the stomach has formed a clear pylorus, functional glandular 
cells, and $\mathrm{pH}$ has dropped below 5 (Stroband and Kroon, 1981). As mentioned before, all mouth opening mechanisms, which are present in the juveniles, are now present. This means that piscivorous behavior can now be fully exploited.

Phase 5 (20-... mm SL). The last phase is characterized by the shift in respiratory mechanisms. At $20 \mathrm{~mm}$ length the suprabranchial organ is formed (Haylor and Oyegunwa, 1993). This structural innovation, typical of clariids, enables them to perform aerial respiration (Greenwood, 1961). However, the apparatuses present at that stage appear to be sufficient to allow the required respiratory movements (Hellin and Chardon, 1983; Vandewalle and Chardon, 1991) as no major changes in related structures can be observed.

\section{Evolutionary Shift in Mouth Opening Mechanisms}

Finally, a brief comment concerning the evolutionary background of mouth opening mechanisms is offered. The hyoid mechanism, in which hyoid depression is ligamentously coupled to mouth opening, is suggested to be a synapomorphic feature of Teleostomi (Lauder and Liem, 1980; Lauder, 1980a). It is only from the halecostomian level on that the opercular mechanism takes part in mouth opening (Lauder, 1980a; Liem, 1991). The increasing importance of the opercular bone is also suggested by modifications that increase its mobility from the halecostomian level on (Schaeffer and Rosen, 1961). Apparently, the ontogenetic shift in mouth opening mechanisms is reflected in the evolutionary trend for improving mouth opening.

\section{CONCLUSIONS}

In relation to their accelerated development, early stages of Clarias gariepinus appear to be a compromise between the availability of cranial structures and functional demands that may have to be coped with. The rudimentary cranial morphology appears to be sufficient to form a mouth opening mechanism which may sustain the respiratory requirements, whereas the timing of yolk sac depletion appears to be related to the formation of improved mouth opening mechanisms. It is highly probable that the subsequent shift and protagonist action of mouth opening mechanisms is, to some degree, related to the shift in feeding mode: suction feeding vs. grasping. The increase in functional demands of feeding and respiratory requirements is reflected in the increase in complexity of the related apparatuses. In $C$. gariepinus, no critical periods that would require synchronous shifts in mouth opening mechanisms appear to be present.

\section{ACKNOWLEDGMENTS}

The authors thank F. Ollevier and F. Volckaert (KUL) for the material of the ontogenetic series, and Mr. Fleure (the Netherlands) for the juvenile specimens. We thank G. De Wever and D. Vandenbroeck for making the serial sections.

\section{LITERATURE CITED}

Adriaens D, Verraes W. 1994. On the functional significance of the loss of the interhyal during ontogeny in Clarias gariepinus Burchell, 1822 (Teleostei : Siluroidei). Belg J Zool 124:139-155.

Adriaens D, Verraes W. 1996. Ontogeny of cranial musculature in Clarias gariepinus (Siluroidei: Clariidae): the adductor mandibulae complex. J Morphol 229:255-269.

Adriaens D, Verraes W. 1997a. The ontogeny of the chondrocranium in Clarias gariepinus: trends in siluroids. J Fish Biol 50:1221-1257.

Adriaens D, Verraes W. 1997b. Ontogeny of the hyoid musculature in the African catfish, Clarias gariepinus (Burchell, 1822) (Siluroidei: Clariidae). Zool J Linn Soc 121:105-128.

Adriaens D, Verraes W. 1997c. Ontogeny of the maxillary barbel muscles in Clarias gariepinus (Siluroidei: Clariidae), with some notes on the palatine-maxillary mechanism. J Zool Lond 241: 117-133.

Adriaens D, Verraes W. 1997d. Ontogeny of the suspensorial and opercular muscles in Clarias gariepinus (Siluroidei: Clariidae), and the consequences for respiratory movements. Neth J Zool 47:61-89.

Adriaens D, Verraes W. 1997e. Some consequences of transformations in siluriform chondrocrania: a case study of Clarias gariepinus (Burchell, 1822) (Siluriformes: Clariidae). Neth J Zool 47:349-363.

Adriaens D, Verraes W. 1998. Ontogeny of the osteocranium in the African catfish, Clarias gariepinus (1822) (Siluriformes: Clariidae): ossification sequence as a response to functional demands. J Morphol 235:183-237.

Adriaens D, Verraes W, Taverne L. 1997. The cranial lateral-line system in Clarias gariepinus (Burchell, 1822) (Siluroidei: Clariidae): morphology and development of canal related bones. Eur J Morphol 35:181-208.

Aerts P. 1987. Aspecten Van De Voedelopname Bij Beenvissen: Functioneel-Anatomisch Onderzoek Van Astatotilapia Elegans (Trewavas, 1933) (Teleostei: Cichlidae). PhD thesis, Ghent.

Aerts P, Verraes W. 1984. Theoretical analysis of a planar four bar system in the teleostean skull: the use of mathematics in biomechanics. Ann Soc R Zool Belg 114:273-290.

Aerts P, Verraes W. 1987. Do inertial effects explain maximal rotation of the maxilla in the rainbow trout (Salmo gairdneri) during feeding? Ann Soc R Zool Belg 117:221-235.

Aerts P, Vanden Berghe W, Verraes W. 1985. Angulo-articular inclination and fast jaw depression in Astatotilapia elegans (Trewavas): different ways of using strain energy. Proc V Congr Eur Ichthyol 97-100.

Aerts P, Osse JWM, Verraes W. 1987. Model of jaw depression during feeding in Astatotilapia elegans (Teleostei: Cichlidae): mechanisms for energy storage and triggering. J Morphol 194: 85-109.

Alexander RM. 1965. Structure and function in the catfish. J Zool (Lond) 148:88-152.

Alexander RM. 1967. The functions and mechanisms of the protrusible upper jaws of some acanthopterygian fish. J Zool (Lond) 151:43-64.

Alexander RM. 1970. Mechanics of the feeding action of various teleost fishes. J Zool (Lond) 162:145-156.

Anker GCh. 1974. Morphology and kinetics of the head of the stickleback, Gasterosteus aculeatus. Trans Zool Soc Lond 32: 311-416.

Cook A. 1996. Ontogeny of feeding morphology and kinematics in juvenile fishes: a case study of the cottid fish Clinocottus analis. J Exp Biol 199:1961-1971. 
Coughlin DJ. 1994. Suction prey capture by clownfish larvae (Amphiprion perideraion). Copeia 1:242-246.

De La Hoz EU, Aldunate R. 1994. El sistema hioideo-mandibular de Cheiorodon (Ostariophysi, Characidae): una innovacion funcional. Ann Mus Nat Valparaiso 22:83-90.

de Visser J, Barel CDN. 1996. Architectonic constraints on the hyoid's optimal starting position for suction feeding of fish. J Morphol 228:1-18.

Drost MR, Muller M, Osse JWM. 1988. A quantitative hydrodynamical model of suction feeding in larval fishes: the role of frictional forces. Proc R Soc Lond (B) 234:263-281.

Elshoud GCA. 1978. Respiration in the three-spined stickleback, Gasterosteus aculeatus L.; an electromyographic approach. Neth J Zool 28:524-544.

Elshoud-Oldenhave MJW, Osse JWM. 1976. Functional morphology of the feeding system in the ruff - Gymnocephalus cernua (L. 1758) - (Teleostei, Percidae). J Morphol 150:399-422.

Fuiman LA. 1997. What can flatfish ontogenies tell us about pelagic and benthic lifestyles? J Sea Res 37:257-267.

Galis F, de Jong PW. 1988. Optimal foraging and ontogeny: food selection by Haplochromis piceatus. Oecologia 75:175-184.

Galis F, Terlouw A, Osse JWM. 1994. The relation between morphology and behaviour during ontogenetic and evolutionary changes. J Fish Biol 45(Suppl. A):13-26.

Ghiot F, Vandewalle P, Chardon M. 1984. Comparaison anatomique et fonctionnelle des muscles et des ligaments en rapport avec les barbillons chez deux familles apparentées de poissons Siluriformes Bagroidei. Ann Soc Roy Zool Belg 114:261-272.

Gill AB. 1997. The role of the mouth morphology in determining threespine stickleback (Gasterosteus aculeatus) feeding behaviour. J Morphol 232:258.

Greenwood PH. 1955. Reproduction in the cat-fish, Clarias mossambicus Peters. Nature 176:516-518.

Greenwood PH. 1961. A revision of the genus Dinotopterus Blgr. (Pisces, Clariidae) with notes on the comparative anatomy of the suprabranchial organs in the Clariidae. Bull Br Mus Nat Hist (Zool) 7:217-241.

Groenewald AAvJ. 1964. Observations on the food habitats of Clarias gariepinus Burchell, the South African freshwater barbel (Pisces: Clariidae) in Transvaal. Hydrobiologia 23:287-291.

Haylor GS, Oyegunwa O. 1993. Onset of air breathing and development of accessory breathing organs in relation to temperature in the African catfish, Clarias gariepinus (Burchell). Aquacult Fish Manag 24:253-260.

Hecht T, Appelbaum S. 1987. Notes on the growth of Israeli sharptooth catfish (Clarias gariepinus) during the primary nursing phase. Aquaculture 63:195-204.

Hecht T, Appelbaum S. 1988. Observations on intraspecific aggression and coeval sibling cannibalism by larval and juvenile Clarias gariepinus (Clariidae: Pisces) under controlled conditions. J Zool (Lond) 214:21-44.

Hellin B, Chardon M. 1983. Observations sur le traject de l'air durant la respiration aérienne chez Clarias lazera Cuvier et Valenciennes, 1840. Ann Soc R Zool Belg 113:97-106.

Holden KK, Bruton MN. 1994. The early ontogeny of the mouthbrooder, Pseudocrenilabrus philander (Pisces, Cichlidae). Environ Biol Fish 41:311-329.

Hunt von Herbing I. 1997. Ontogeny of feeding mechanisms in larval fish with different life histories: winter flounder versus Atlantic cod. J Morphol 232:267.

Hunt von Herbing I, Miyake T, Hall BK, Boutilier RG. 1996a. Ontogeny of feeding and respiration in larval Atlantic cod Gadus morhua (Teleostei, Gadiformes). II. Function. J Morphol 227:37-50.

Hunt von Herbing I, Miyake T, Hall BK, Boutilier RG. 1996b. Ontogeny of feeding and respiration in larval Atlantic cod Gadus morhua (Teleostei, Gadiformes). I. Morphology. J Morphol 227:15-35.

Johnson GD. 1992. Monophyly of the euteleostean clades Neoteleostei, Eurypterygii, and Ctenosquamata. Copeia 1:825

Kamler E, Szlaminska M, Kuczynski M, Hamackova J, Kouril J, Dabrowski R. 1994. Temperature-induced changes of early de- velopment and yolk utilization in the African catfish Clarias gariepinus. J Fish Biol 44:311-326.

Kohno H, Ordonio-Aguilar R, Ohno A, Taki Y. 1996a. Morphological aspects of feeding and improvement in feeding ability in early stage larvae of the milkfish, Chanos chanos. Ichthyol Res 43:133-140

Kohno H, Ordonio-Aguilar R, Ohno A, Taki Y. 1996b. Osteological development of the feeding apparatus in early stage larvae of the seabass, Lates calcarifer. Ichthyol Res 43:1-9.

Lauder GV. 1979. Feeding mechanics in primitive teleosts and in the halecomorph fish Amia calva. J Zool (Lond) 187:543-578.

Lauder GV. 1980a. Evolution of the feeding mechanism in primitive actinopterygian fishes: a functional anatomical analysis of Polypterus, Lepisosteus and Amia. J Morphol 163:283-317.

Lauder GV. 1980b. The role of the hyoid apparatus in the feeding mechanism of the coelacanth Latimeria chalumnae. Copeia $1: 1-9$.

Lauder GV. 1981. Intraspecific functional repertoires in the feeding mechanism of the Characoid fishes Lebiasina, Hoplias and Chalceus. Copeia 1:154-168.

Lauder GV. 1982. Patterns of evolution in the feeding mechanism of actinopterygian fishes. Am Zool 22:275-285.

Lauder GV, Liem KF. 1980. The feeding mechanism and cephalic myology of Salvelinus fontenalis: form, function, and evolutionary significance. In: Balon EK, editor. Charrs, salmonid fishes of the genus Salvelinus. Den Hague, Netherlands: Dr. W. Junk. pp 365-390.

Lauder GV, Liem KF. 1989. The role of historical factors in the evolution of complex organismal functions. In: Wake DB, Roth G, editors. Complex organismal functions: integration and evolution in vertebrates. Life Sciences Research Report 45. New York: John Wiley \& Sons. p 63-78.

Lauder GV, Crompton AW, Gans C, Hanken J, Liem KF, Maier WP, Meyer A, Presley R, Rieppel OC, Roth G, Schluter D, Zweers GA. 1989. Group report: how are feeding systems integrated and how have evolutionary innovations been introduced? In: Wake DB, Roth G, editors. Complex organismal functions: integration and evolution in vertebrates. Life Sciences Research Report 45. New York: John Wiley \& Sons. p 97-115.

Liem KF. 1984. The muscular basis of aquatic and aeral ventilation in the air-breathing teleost fish Channa. J Exp Biol 113: $1-18$.

Liem KF. 1991. A functional approach to the development of the head of teleosts: implications on constructional morphology and constraints. In: Schmidt-Kittler N, Vogel K, editors. Constructional morphology and evolution. Berlin: Springer-Verlag. $\mathrm{p}$ 231-249.

Lowe CG, Wetherbee BM, Crow GL, Tester AL. 1996. Ontogenetic dietary shifts and feeding behavior of the tiger shark, Galeocerdo cuvieri, in Hawaiian waters. Environ Biol Fish 47:203211.

Muller M. 1987. Optimization principles applied to the mechanism of neurocranium levation and mouth bottom depression in bony fishes (Halecostomi). J Theor Biol 126:343-368.

Muller M, Osse JWM. 1984. Hydrodynamics of suction feeding in fish. Trans Zool Soc Lond 37:51-135.

Olson MH. 1996. Ontogenetic niche shifts in largemouth bass: variability and consequences for first-year growth. Ecology 77: 179-190.

Osse JWM. 1969. Functional morphology of the head of the perch (Perca fluviatilis L.): an electromyographic study. Neth J Zool 19:289-392.

Osse JWM. 1989. A functional explanation for a sequence of developmental events in the carp. The absence of gills in early larvae. Acta Morphol Neerland Scand 27:111-118.

Osse JWM. 1990. Form changes in fish larvae in relation to changing demands of function. Neth J Zool 40:362-385.

Osse JWM, Drost MR. 1989. Hydrodynamics and mechanics of fish larvae. Polsk Arch Hydrobiol 36:455-465.

Osse JWM, van den Boogaart JGM. 1995. Fish larvae, development, allometric growth, and the aquatic environment. ICES Mar Sci Symp 201:21-34. 
Osse JWM, van den Boogaart JGM, van Snik GMJ, van der Sluys L. 1997. Priorities during early growth of fish larvae. Aquaculture 155:249-258.

Otten E. 1982. The development of a mouth-opening mechanism in a generalized Haplochromis species: $H$. elegans Trewavas 1933 (Pisces, Cichlidae). Neth J Zool 32:31-48.

Radermaker F, Surlemont C, Sanna P, Chardon M, Vandewalle P. 1989. Ontogeny of the Weberian apparatus of Clarias gariepinus (Pisces, Siluriformes). Can J Zool 67:2090-2097.

Rowe DK, Chisnall BL. 1996. Ontogenetic habitat shifts by Galaxias galaxias (Galaxiidae) between the littoral and limnetic zones of Lake Kanono, New Zealand. Environ Biol Fish 46:255264.

Schaefer SA. 1987. Osteology of Hypostomus plecostomus (Linnaeus) with a phylogenetic analysis of the loricariid subfamilies (Pisces: Siluroidei). Contrib Sci 394:1-31.

Schaefer SA, Lauder GV. 1996. Testing historical hypotheses of morphological change: biomechanical decoupling in loricarioid catfishes. Evolution 50:1661-1675.

Schaeffer B, Rosen DE. 1961. Major adaptive levels in the evolution of the actinopterygian feeding mechanism. Am Zool 1:187204.

Segnini S, Bastardo H. 1995. Cambios ontogenéticos en la dieta de la trucha arcoiris (Oncorhynchus mykiss) en un Rio Andino neotropical. Biotropica 27:495-508.

Stiassny MLJ. 1996. Basal ctenosquamate relationships and the interrelationships of the myctophiform (scopelomorph) fishes. In: Stiassny MLJ, Parenti LR, Johnson GD, editors. Interrelationships of fishes. London: Academic Press. p 405-426.

Stroband HWJ, Kroon AG. 1981. The development of the stomach in Clarias lazera and the intestinal absorption of protein macromolecules. Cell Tissue Res 215:397-415.

Surlemont C, Vandewalle P. 1991. Développement postembryonnaire du squelette et de la musculature de la tête de Clarias gariepinus (Pisces, Siluriformes) depuis l'eclosion jusqu'à 6,8 mm. Can J Zool 69:1094-1103.

Surlemont C, Chardon M, Vandewalle P. 1989. Skeleton, muscles and movements of the head of a $5,2 \mathrm{~mm}$ fry of Clarias gariepinus (Burchell) (Pisces Siluriformes). Fortsch Zool/ Prog Zool 35.

Teugels GG. 1986. A systematic revision of the African species of the genus Clarias (Pisces, Clariidae). Ann Mus R Afr Centr Sci Zool 247:1-199.

Thomas JD. 1966. On the biology of the catfish Clarias senegalensis, in a man-made lake in the Ghanaian savanna with particular reference to its food habits. J Zool (Lond) 148:476514.

Vandewalle P, Chardon M. 1991. A new hypothesis on the air flow in air breathing in Clarias gariepinus (Teleostei, Siluriformes). Belg J Zool 121:73-80.

Vandewalle P, Surlemont C, Sanna P, Chardon M. 1985. Interprétation fonctionnelle de modifications du splanchnocrâne pendant le développement post-embryonnaire de Clarias gariepinus (Téléostéens, Siluriformes). Zool Jb Anat 113:91100.

Verraes W. 1977. Postembryonic ontogeny and functional anatomy of the ligamentum mandibulo-hyoideum and the ligamentum interoperculo-mandibulare, with notes on the opercular bones and some other cranial elements in Salmo gairdneri Richardson, 1836 (Teleostei: Salmonidae). J Morphol 151:111120.

Wainwright PC, Turingan RG. 1993. Coupled versus uncoupled functional systems: motor plasticity in the queen triggerfish Balistes vetula. J Exp Biol 180:209-227.

Weibel ER, Taylor CR. 1981. Design of the mammalian respiratory system. Resp Physiol 44:1-164.

Westneat MW. 1990. Feeding mechanics of teleost fishes (Labridae; Perciformes): a test of four-bar linkage models. J Morphol 205:269-295.

Westneat MW. 1994. Transmission of force and velocity in the feeding mechanisms of labrid fishes (Teleostei, Perciformes). Zoomorphology 114:103-118.

Westneat MW, Wainwright PC. 1989. Feeding mechanism of Epibulus insidiator (Labridae; Teleostei): evolution of a novel functional system. J Morphol 202:129-150. 